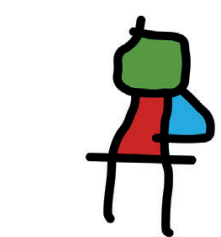

SEICAIP

\section{Allergologia et immunopathologia}

Sociedad Española de Inmunología Clínica, Alergología y Asma Pediátrica

REVIEW

www.all-imm.com

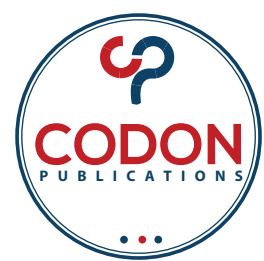

OPEN ACCESS C(1)(0)

\title{
Chronic cough in childhood: A systematic review for practical guidance by the Italian Society of Pediatric Allergy and Immunology
}

\author{
Gian Luigi Marsegliaa, Sara Manti ${ }^{b}$, Elena Chiappinic, Ilaria Brambilla ${ }^{a}$, Carlo Caffarelli ${ }^{\mathrm{d}}$, \\ Mauro Calvanie, Fabio Cardinale ${ }^{f}$, Claudio Cravidis, Marzia Duse ${ }^{\mathrm{h}}$, Alberto Martelli', \\ Domenico Minasij, Michele Miraglia del Giudice ${ }^{k}$, Giovanni Pajnol, Diego G. Peronim \\ Maria Angela Tosca ${ }^{n}$, Amelia Licaria ${ }^{a}$ Giorgio Ciprandi**
}

\author{
aPediatric Clinic, Pediatrics Department, Policlinico San Matteo, University of Pavia, Pavia, Italy \\ ${ }^{b}$ Pediatric Respiratory Unit, Department of Clinical and Experimental Medicine, University of Catania, Catania, Italy \\ Infectious Disease Unit, Meyer Children's Hospital, Department of Science Health, University of Florence, Florence, Italy \\ dPediatric Clinic, Mother-Child Department, University of Parma, Parma, Italy \\ 'Operative Unit of Pediatrics, S. Camillo-Forlanini Hospital, Rome, Italy \\ fPediatric Unit, Azienda Ospedaliero-Universitaria "Policlinico-Giovanni XXIII", Bari, Italy \\ ${ }^{\text {s} A S S T}$-Pavia, Pavia, Italy \\ hDepartment of Pediatrics, Sapienza University of Rome, Rome, Italy \\ 'Pediatric Unit, ASST-Rhodense, Garbagnate Milanese (MI), Italy \\ ${ }^{j}$ Pediatric Unit, Grande Ospedale Metropolitano, Reggio Calabria, Italy \\ ${ }^{k}$ Department of Woman and Child and General and Specialized Surgery, University of Campania Luigi Vanvitelli, Naples, Italy \\ 'Department of Pediatrics, Allergy Unit, University of Messina, Messina, Italy \\ mPediatric Clinic, University of Pisa, Pisa, Italy \\ ${ }^{n}$ Allergy Center, Istituto Giannina Gaslini, Genoa, Italy \\ ${ }^{\circ}$ Allergy Clinic, Casa di Cura Villa Montallegro, Genoa, Italy
}

Received 4 August 2020; Accepted 15 November 2020

Available online 1 March 2021

\section{KEYWORDS \\ adolescents; \\ algorithm; \\ children; \\ chronic cough; \\ diagnosis; \\ dry cough; \\ wet cough}

\begin{abstract}
The current systematic review presented and discussed the most recent studies on pediatric chronic cough. In addition, the Italian Society of Pediatric Allergy and Immunology elaborated a comprehensive algorithm to guide the primary care approach to a pediatric patient with chronic cough.

Several algorithms on chronic cough management have been adopted and validated in clinical practice; however, unlike the latter, we developed an algorithm focused on pediatric age, from birth until adulthood. Based on our findings, children and adolescents with chronic cough without cough pointers can be safely managed, initially using the watchful waiting approach
\end{abstract}

${ }^{*}$ Corresponding author: Giorgio Ciprandi, MD, Allergy Department, Via P. Boselli 5, 16146 Genoa, Italy. Email address: gio.cip@libero.it 
and, successively, starting empirical treatment based on cough characteristics. Unlike other algorithms that suggest laboratory and instrumental investigations as a first step, this review highlighted the importance of a "wait and see" approach, consisting of parental reassurance and close clinical observation, also due to inter-professional collaboration and communication between general practitioners and specialists that guarantee better patient management, appropriate prescription behavior, and improved patient outcome. Moreover, the neonatal screening program provided by the Italian National Health System, which intercepts several diseases precociously, allowing to treat them in a very early stage, helps and supports a "wait and see" approach.

Conversely, in the presence of cough pointers or persistence of cough, the patient should be tested and treated by the specialist. Further investigations and treatments will be based on cough etiology, aiming to intercept the underlying disease, prevent potentially irreversible tissue damage, and improve the general health of patients affected by chronic cough, as well as the quality of life of patients and their family.

Further high-quality randomized controlled trials are needed to validate this algorithm's performance in real clinical practice.

(c) 2021 Codon Publications. Published by Codon Publications.

\section{Overview}

Cough is defined as "a forced expulsive maneuver, usually against a closed glottis, and is associated with a characteristic sound." Cough is a protective physiological reflex deputed to clear secretion from the airways or remove inhaled material. As a physiological reflex, healthy children usually cough on average 11 times (range 1-34) daily. On the other hand, cough may also be the key symptom of diseases affecting the upper or lower respiratory airways, requiring prompt diagnosis and treatment. Cough may be pragmatically classified, considering its duration and characteristics. Conventionally, acute cough lasts less than 4 weeks, whereas chronic cough lasts more than 4 weeks. Cough may be wet, such as productive (associated with secretion), or dry, such as irritative. The current review aims to present and discuss recent evidence on chronic cough. This document, provided by the Italian Society of Pediatric Allergy and Immunology (SIAIP), proposes a practical algorithm to manage and improve clinical outcomes of children and adolescents with a chronic cough in clinical practice.

\section{Pathophysiological mechanisms}

Cough is a multifaceted neuromuscular phenomenon characterized by three dynamic steps: a deep inspiration, an exaggerated expiratory effort against the closed glottis, and the opening of the glottis, closure of the nasopharynx, and forced and exaggerate airflow emission through the mouth. ${ }^{1}$ These events are orchestrated by the sequential activation and coordination of an afferent circuit, a central processing pathway, and an efferent arm. ${ }^{2}$

Cough receptors are generally in the larynx, trachea, bronchi, and pleura, and also the nose and paranasal sinuses, in the auditory canal, pericardium, esophagus, and stomach. Stimulation of these receptors may also elicit the cough. For example, the ear-cough reflex (Arnold's reflex) is known. ${ }^{2}$ The application of an endogenous and/or exogenous stimulus on cough receptors, localized to vagal afferent nerve terminations in the airway's mucosa, activates a complex neuronal response, which, via the release of numerous mediators, induces the cough neural circuits. From multiple peripheral and central sites, the afferent signal is transported to trigger both on-site and distal responses, thus activating the bronchopulmonary sensory nerve as well as peripheral and central sites in the brainstem. Herein, the afferent reflex is modulated, and an efferent response is generated to induce a neuromuscular effect involving laryngeal abductor and adductor muscle, diaphragm, muscles of the chest wall, and cervical and abdominal muscles. ${ }^{3}$

Coughing is a protective reflex that removes foreign bodies entered into airways or enhances airway clearance, acting as an innate, built-in defense mechanism. ${ }^{4}$

However, when it occurs chronically, cough becomes a disruptive health problem for the child/adolescent affected. Chronic cough, defined as a daily cough lasting for $>4$ weeks, ${ }^{5}$ represents a common pediatric health problem, with a prevalence of $35 \%$ in school-age children. ${ }^{6}$ Chronic cough may require multiple physician visits and hospitalization, with substantial implications for the child and patient's family and a relevant burden for healthcare. Accordingly, appropriate diagnostic management has long been recognized as imperative to achieve the correct diagnosis promptly and guarantee the best possible therapy. Although cough is commonly considered to originate from the respiratory system, several extrapulmonary or systemic diseases can cause a chronic cough. This event is frequently observed in children with a nonspecific chronic cough in which, due to the lack of corresponding clinical symptoms, the risk of misdiagnosis and/or underdiagnosis is high. It reflects the importance of both a careful and a multidisciplinary assessment of the affected child/adolescent.

Herein, we performed an updated systematic review regarding the management of chronic cough in children and adolescents; a diagnostic and therapeutic algorithm of a chronic cough has also been developed to offer a practical guide for the pediatrician. 


\section{Methodology}

\section{Study design}

A systematic review was performed according to the Cochrane handbook guidelines. ${ }^{7}$ The Preferred Reporting Items for Systematic Reviews and Meta-Analyses (PRISMA) Statement has been used for reporting of the systematic review, filling a 27 -item checklist and a flow diagram (Figure 1). ${ }^{8}$

\section{Search strategy}

A literature search was performed covering papers published from January 1, 2008 to July 31, 2019; the PubMed and Excerpta Medica Database (EMBASE) databases were systematically searched. In PubMed, the following search strategy was used: "cough" [MeSH] AND "chronic" [All Fields] AND "infant" [MeSH] OR "child" [MeSH] OR "adolescent” [MeSH] OR “children” [MeSH].
In EMBASE, the following search strategy was used: “cough":ab,ti AND “chronic":ab,ti AND "infant"/de OR “child”/de OR “adolescent"/de OR “children.

An additional research was conducted on the Cochrane Database of Systematic Reviews, and the references of relevant articles were further cross-checked.

\section{Inclusion criteria}

Studies were considered eligible if they showed the following characteristics: pediatric population (aged $<18$ years), papers published in English, year of publication (from 2008 to 2019), study design consisting of prospective or retrospective observational studies, and randomized controlled trial (RCT).

\section{Exclusion criteria}

Studies related to the adult population, non-pertinent articles, duplicates, letters, commentaries, case series including

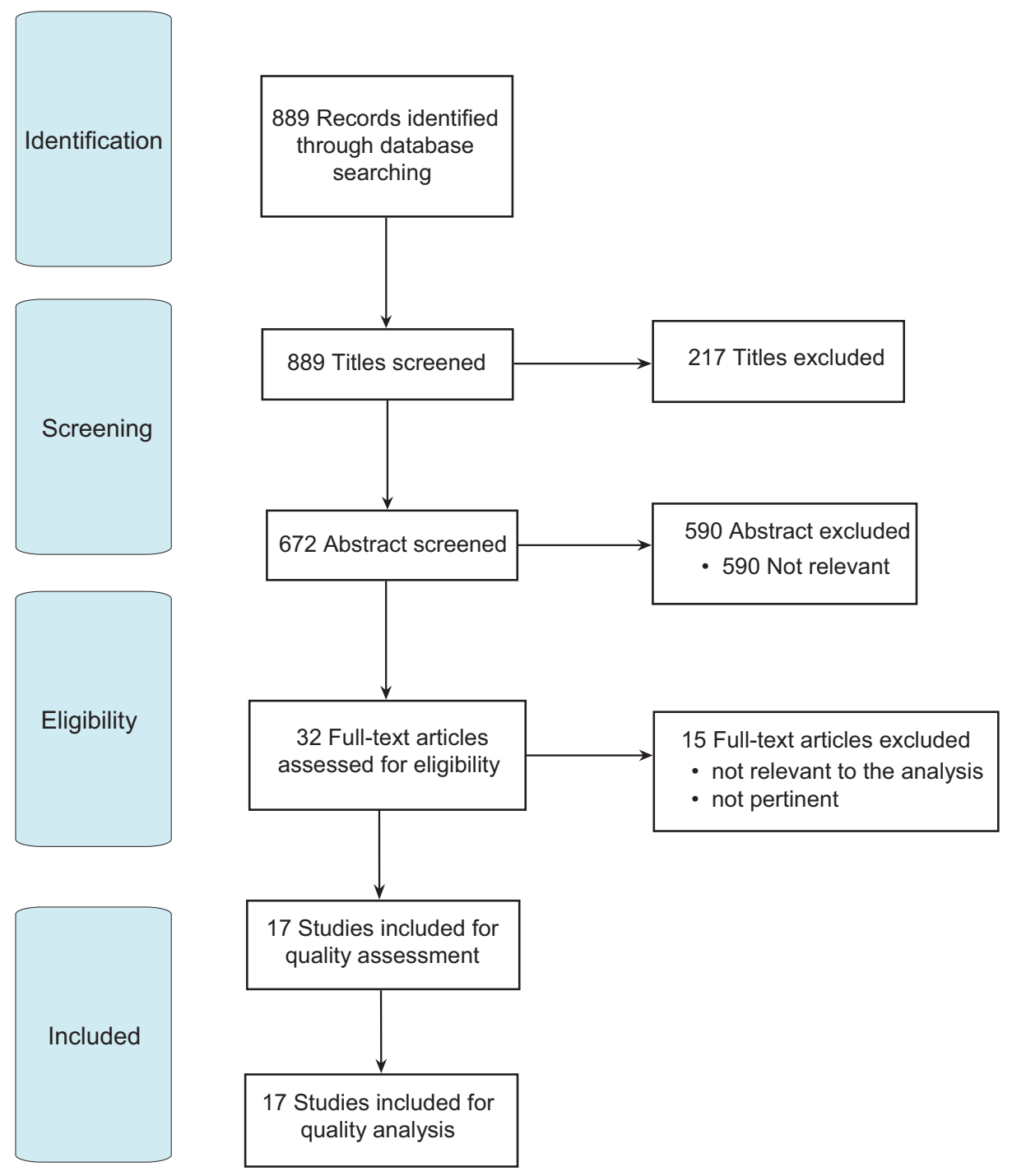

Figure 1 Flow chart of study selection. 
$<10$ children, reviews, guidelines, and articles not written in the English language were excluded from the analysis.

\section{Studies selection}

Studies focusing on the definition of the disease, clinical presentation, and laboratory and instrumental investigations on children with chronic cough were selected.

Titles and abstracts of studies identified during the initial search were screened for inclusion, and papers focusing on chronic cough were included in this review. After that, the full text of all included papers was analyzed for further evaluation. The references of relevant articles were also crosschecked.

\section{Data extraction}

Data were independently extracted by two authors (SM and EC), and any disagreements or conflicts were discussed with other authors.

The following data were extracted for each study: authors, year of publication, the title of the study, location, the number of subjects included, the age of children, study type, number and type of included studies, aims/outcomes, results, and comments/limitations of the study.

The study characteristics are summarized in Table 1.

\section{Results}

\section{Literature findings}

The initial search identified 889 records (306 from the PubMed database and 583 from the EMBASE database) of which 104 were duplicates. One additional record was identified using the Cochrane Database of Systematic Reviews. Thirty-two studies met the inclusion criteria after abstracts and titles were evaluated. Fifteen of these studies were excluded because data were not pertinent or not relevant (Table 2 ); 17 studies (2 systematic reviews, 4 retrospective observational studies, 10 prospective analyses and 1 clinical trial) were judged eligible and included in the final analysis. The search results and the selection process are shown in Figure 1.

\section{Study characteristics}

This systematic review included 17 studies. Overall, 7337 children aged 24 months to 18 years presenting with chronic cough were included in the review. The study settings included emergency departments, pediatric departments, or outpatient clinics and services.

\section{Definition}

The definition of chronic cough is nonunanimous. Most of the studies defined chronic cough as a cough longer than 4 weeks. $^{9-25}$ One study defined chronic cough as lasting more than three consecutive weeks. ${ }^{24}$ Two studies defined chronic cough as a cough of $>8$ weeks duration. ${ }^{5,21}$ Another study, by the age, defined chronic cough as a cough lasting $>4$ weeks in children $<15$ years and $>8$ weeks for adolescents $\geq 15$ years. ${ }^{18}$ Only one study did not make the chronic cough definition explicit. ${ }^{17}$ More recently, according to the latest CHEST Expert Cough Panel guidelines, chronic cough has been defined as the presence of daily cough for more than 4 weeks for children aged $\leq 14$ years. ${ }^{26}$

\section{Clinical history and symptoms}

Chronic cough may be the expression of several diseases. Thus, the ability of the clinician to interpret the clinical history correctly, the type of cough, and the presence of other symptoms is crucial to establishing an accurate differential diagnosis.

Although none of the included studies was explicitly focused on clinical history and presentation of chronic cough in children, ${ }^{9-24}$ it has been noted that positive personal and family history of atopy and a previous history of chronic cough were commonly detected in children affected by chronic cough. ${ }^{11,16,18-20}$ Passive tobacco exposure was commonly reported in patients with chronic cough. ${ }^{11,16,18,20}$

At the time of presentation, the average cough duration differed widely among studies, ranging from $<7$ days to 30.6 weeks. ${ }^{11,22,24}$

Running nose and nasal congestion, dry throat with foreign body sensation, and repeated clearing of the throat often accompanied chronic wet cough that aggravates when the posture is changed or in the early morning. ${ }^{15}$ It can signify an underlying illness, such as aspiration lung disease, cystic fibrosis, or noncystic fibrosis bronchiectasis. ${ }^{9}$

Children with dry cough are more commonly aggravating or onset at night and/or early morning. Dry cough is associated with a high rate of spontaneous resolution without any therapeutic intervention. ${ }^{13}$

Symptoms of post-tussive emesis, purulent nasal discharge, and postnasal drip showed a predictive value for a positive sinus $X$-ray $(p<0.001)$. Worsening cough at night and with exercise did not correlate with sinusitis underlying chronic cough ${ }^{19}$; conversely, these symptoms appeared suggestive, more commonly, of asthma and, less frequently, of gastroesophageal reflux disease (GERD). ${ }^{21}$

\section{Etiology of chronic cough}

The etiology of chronic cough is broad and differs significantly in clinical settings. Airway hyperreactivity, GERD, and infectious diseases were reported as the most common causes underlying a positive history for chronic cough in adults. ${ }^{11}$

By stratifying the pediatric population by age, a significant difference in the etiology of chronic cough appeared per the age range. ${ }^{12,15,18,20}$

In the infant population ( 5 months- 1 year of age), the sequence of the common causes of nonspecific chronic cough was upper airway cough syndrome (33.3\%), cough 


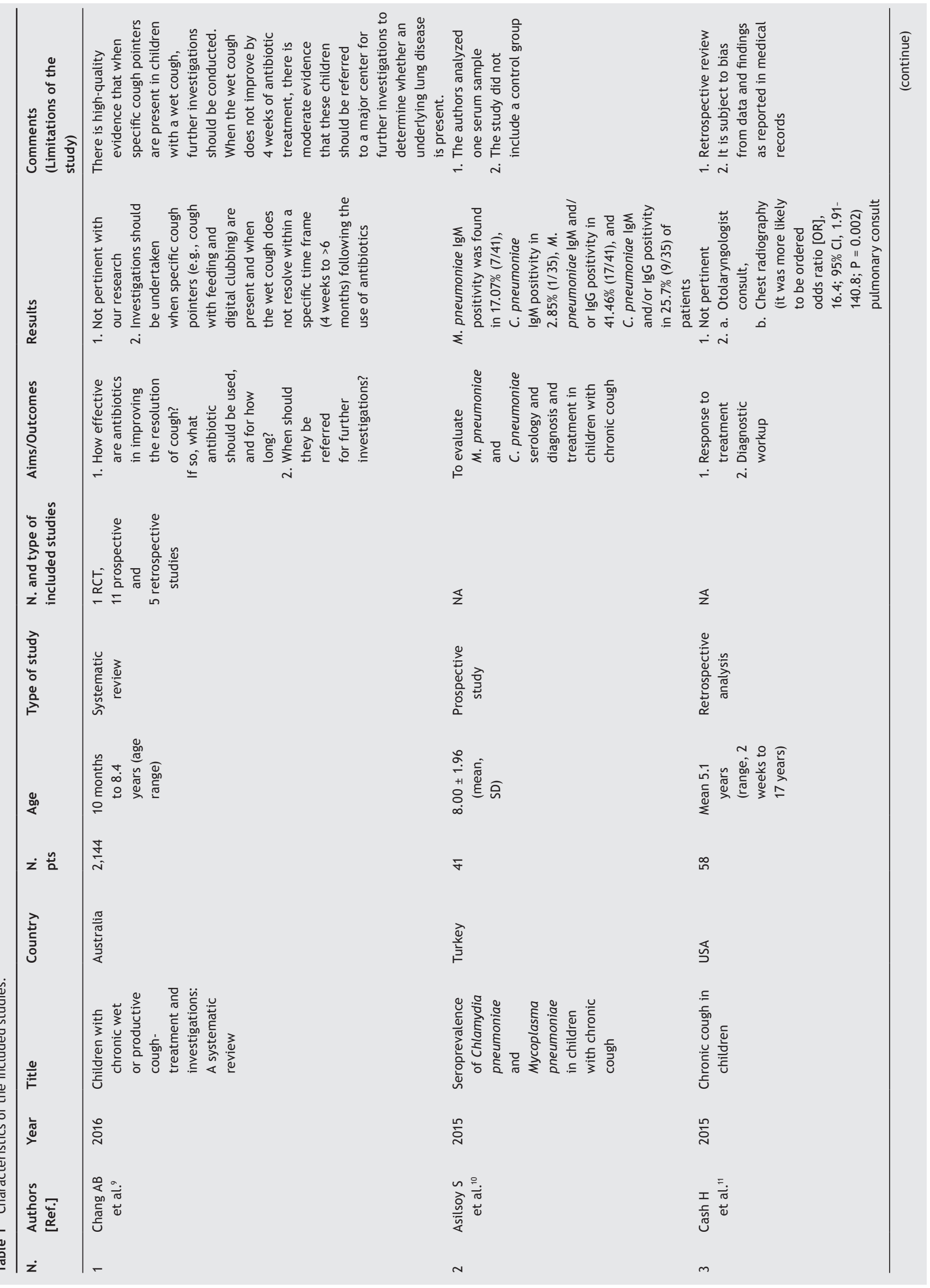




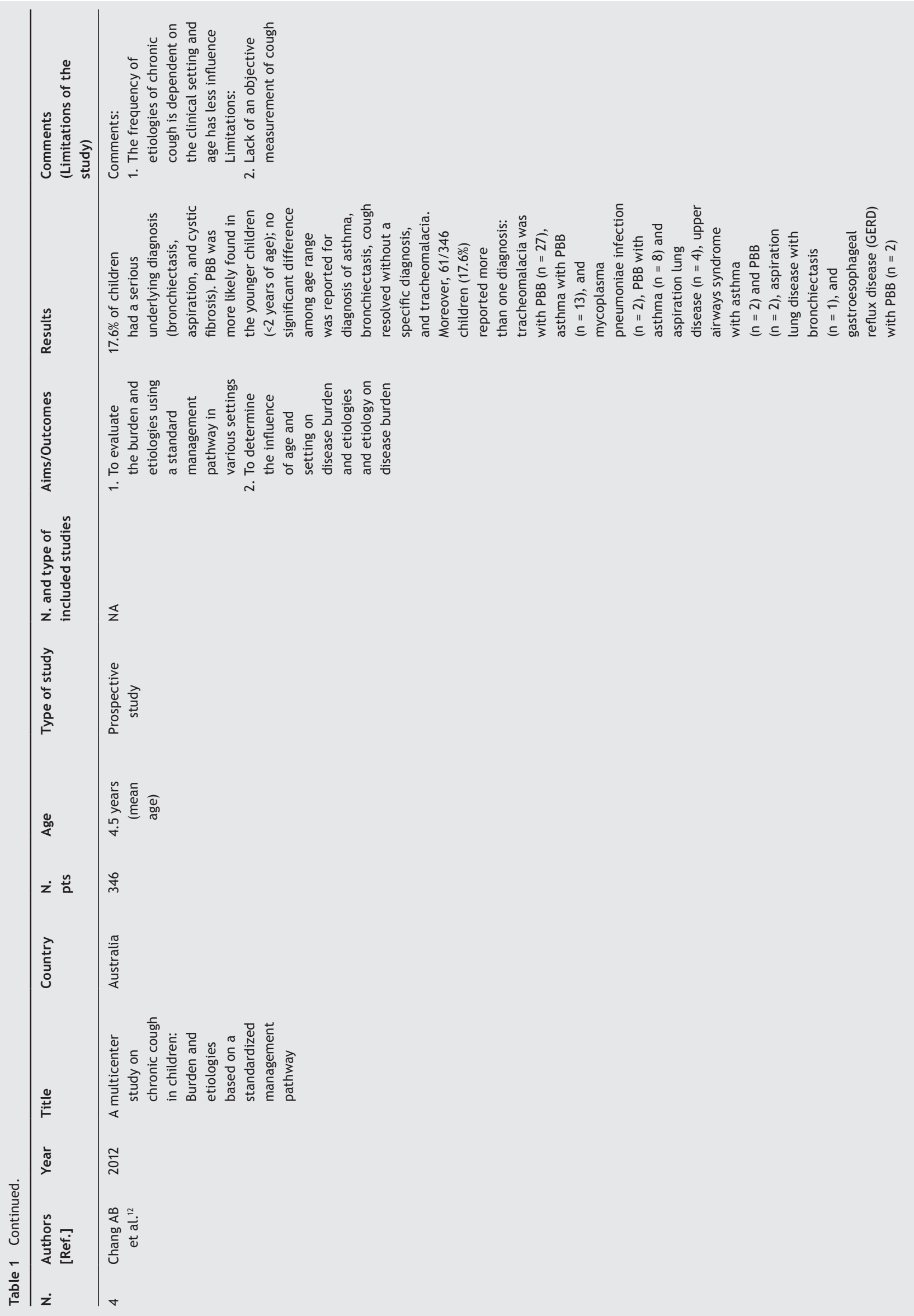



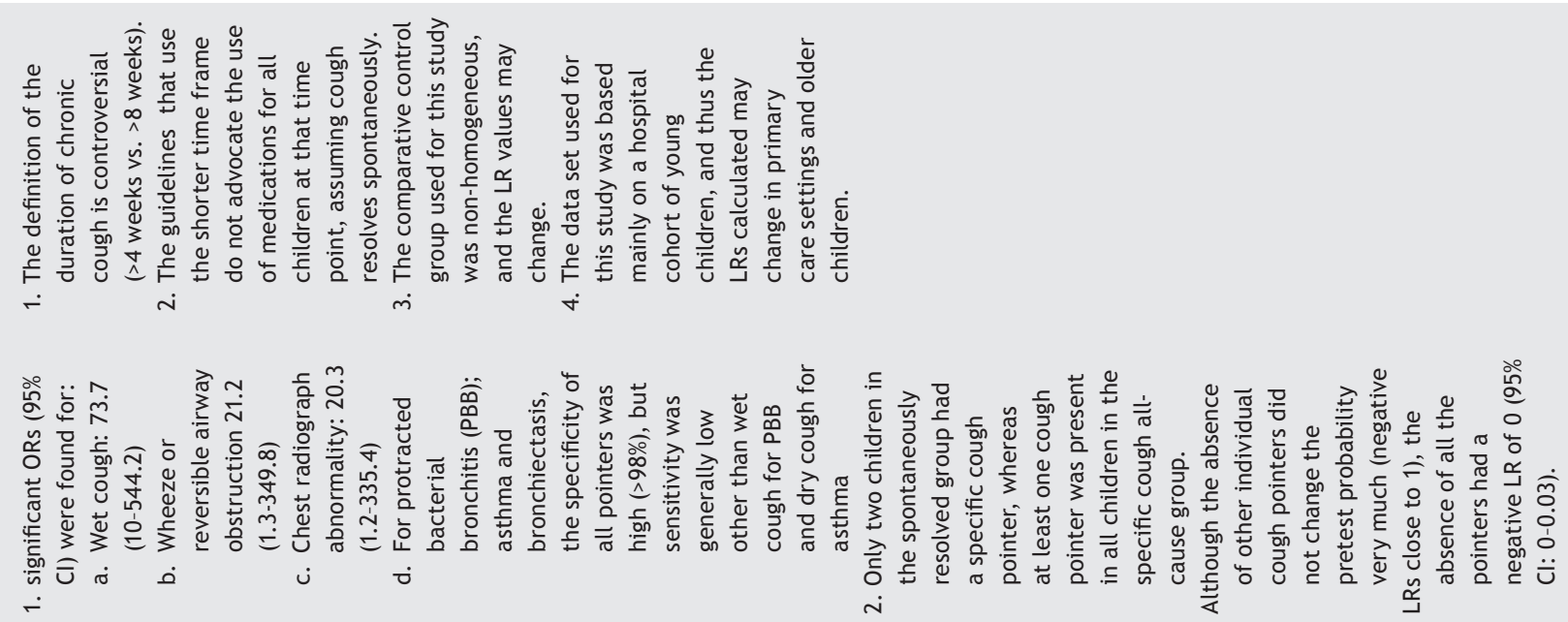

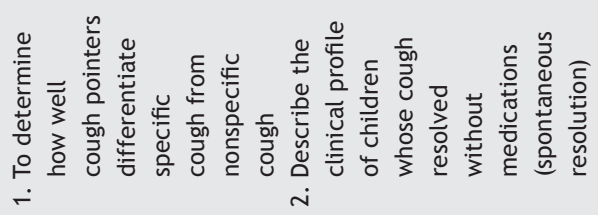

$\stackrel{s}{z}$

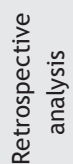

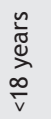

్ల

$\frac{\sqrt{\frac{0}{\pi}}}{\frac{\sqrt[0]{5}}{4}}$

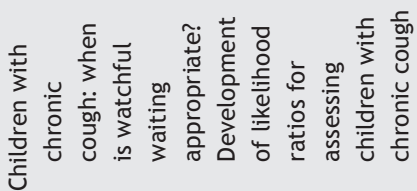

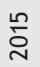

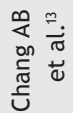

n 


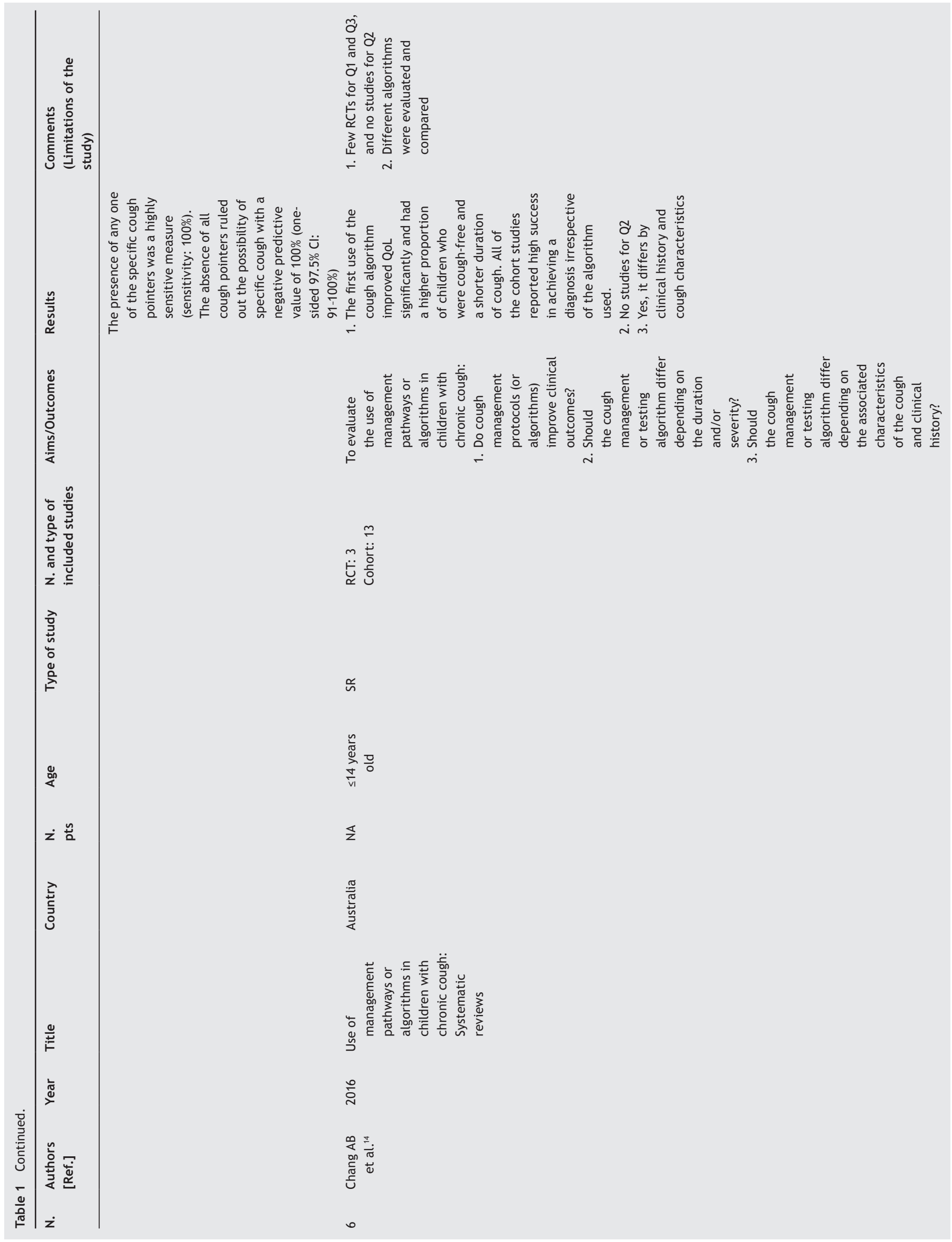



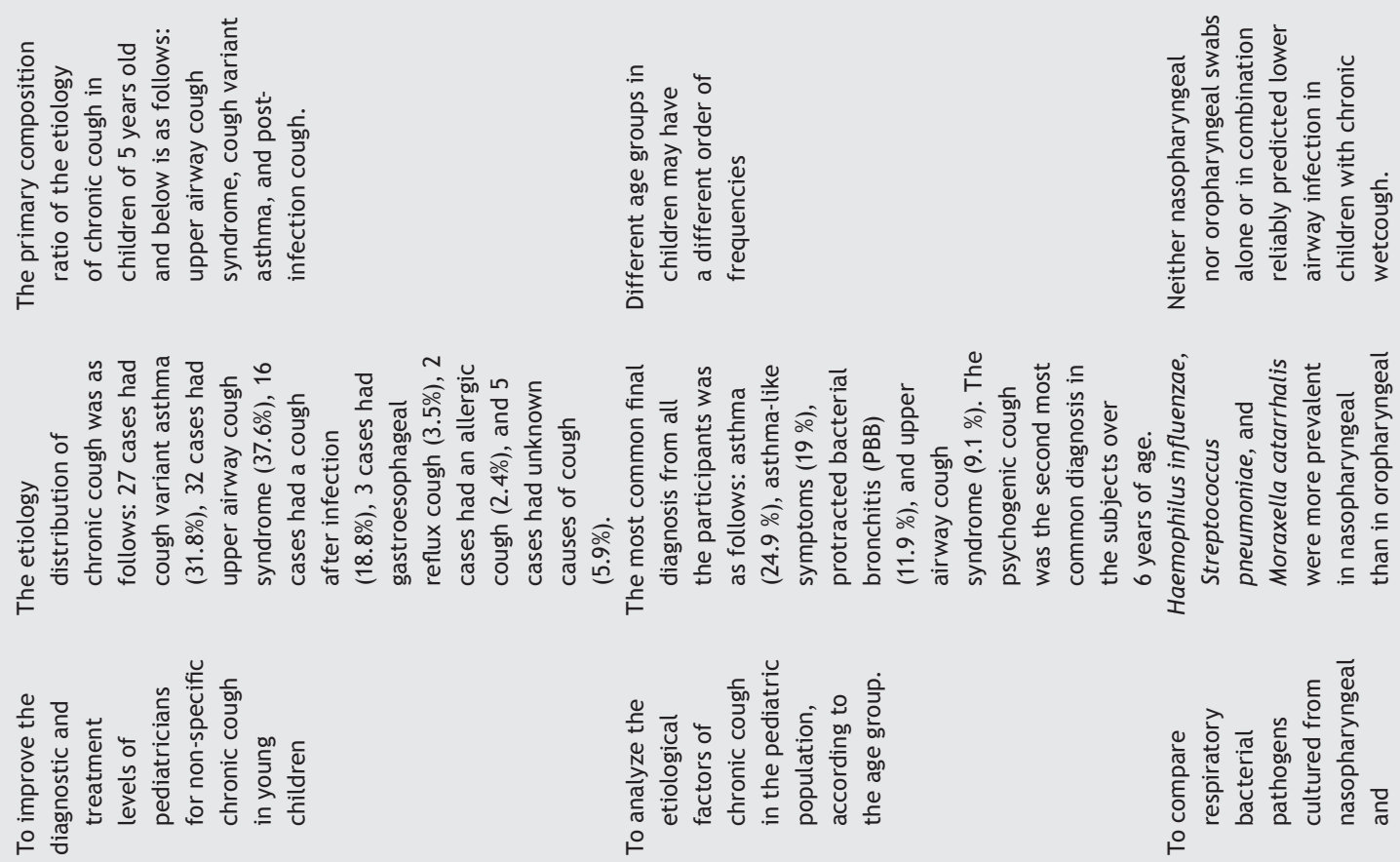

z

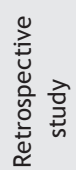

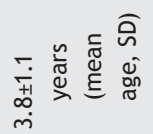

$\stackrel{\infty}{\infty}$

这

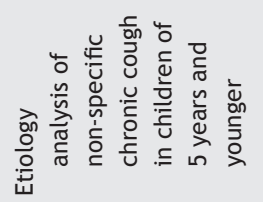

$\stackrel{\infty}{\stackrel{2}{2}}$

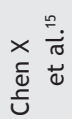

䍃

ڤึำ

產

논 z

竎
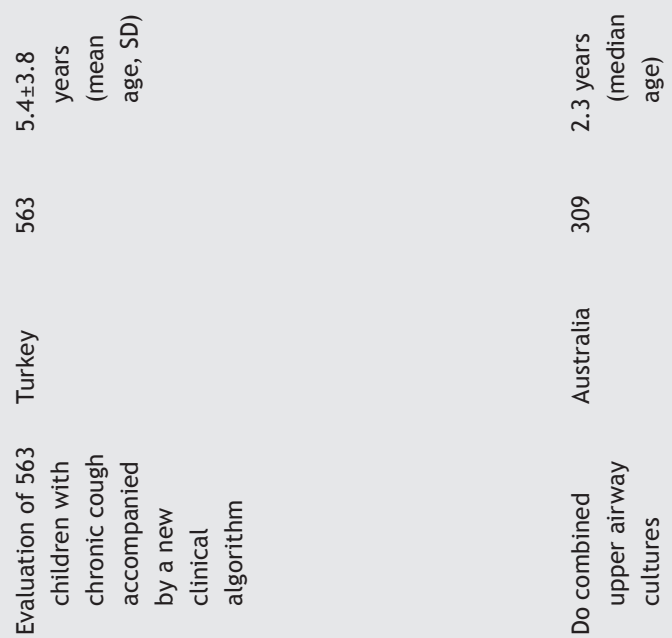

。ํ

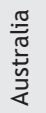

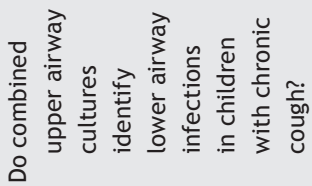

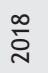

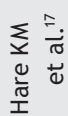




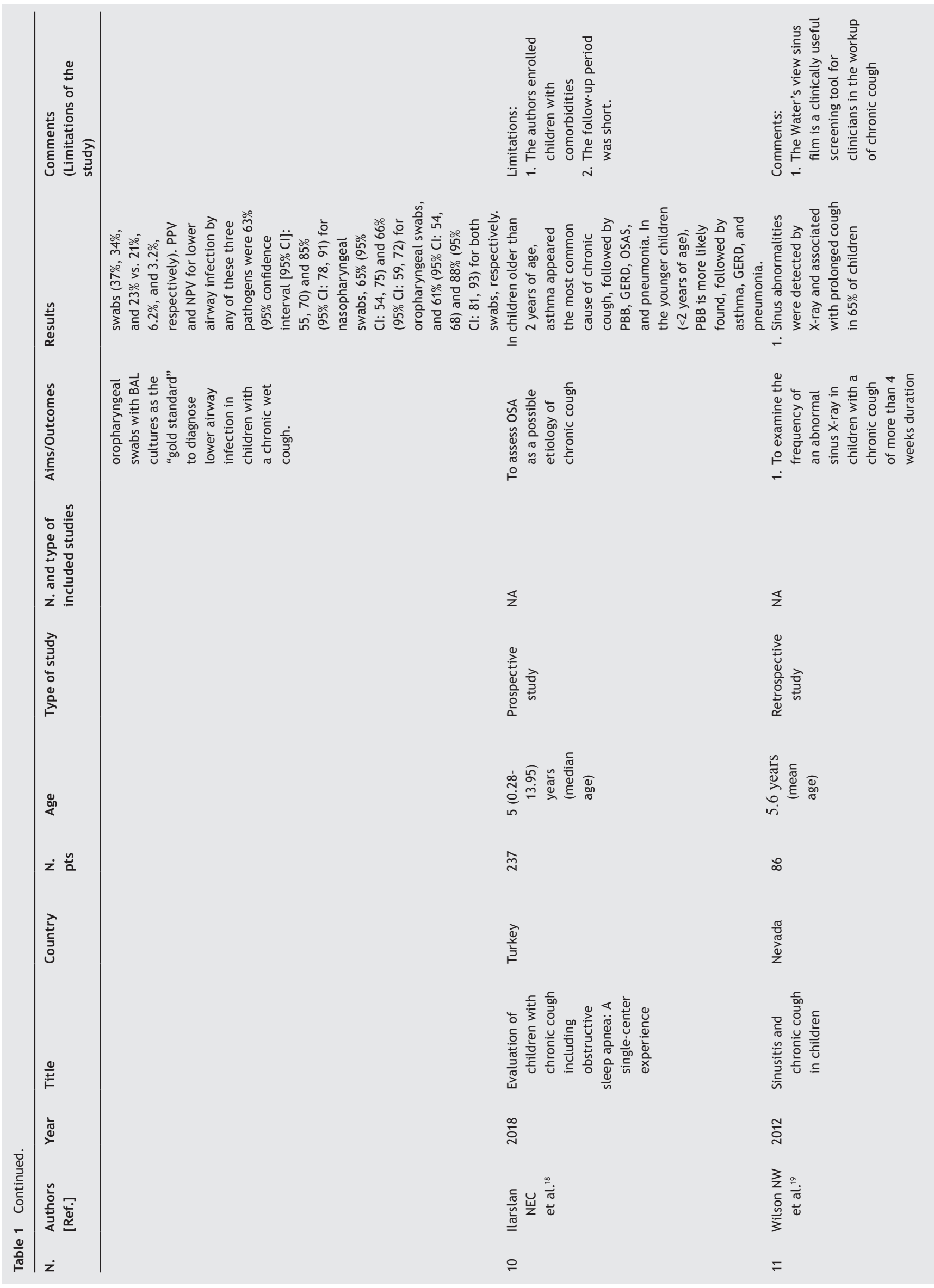




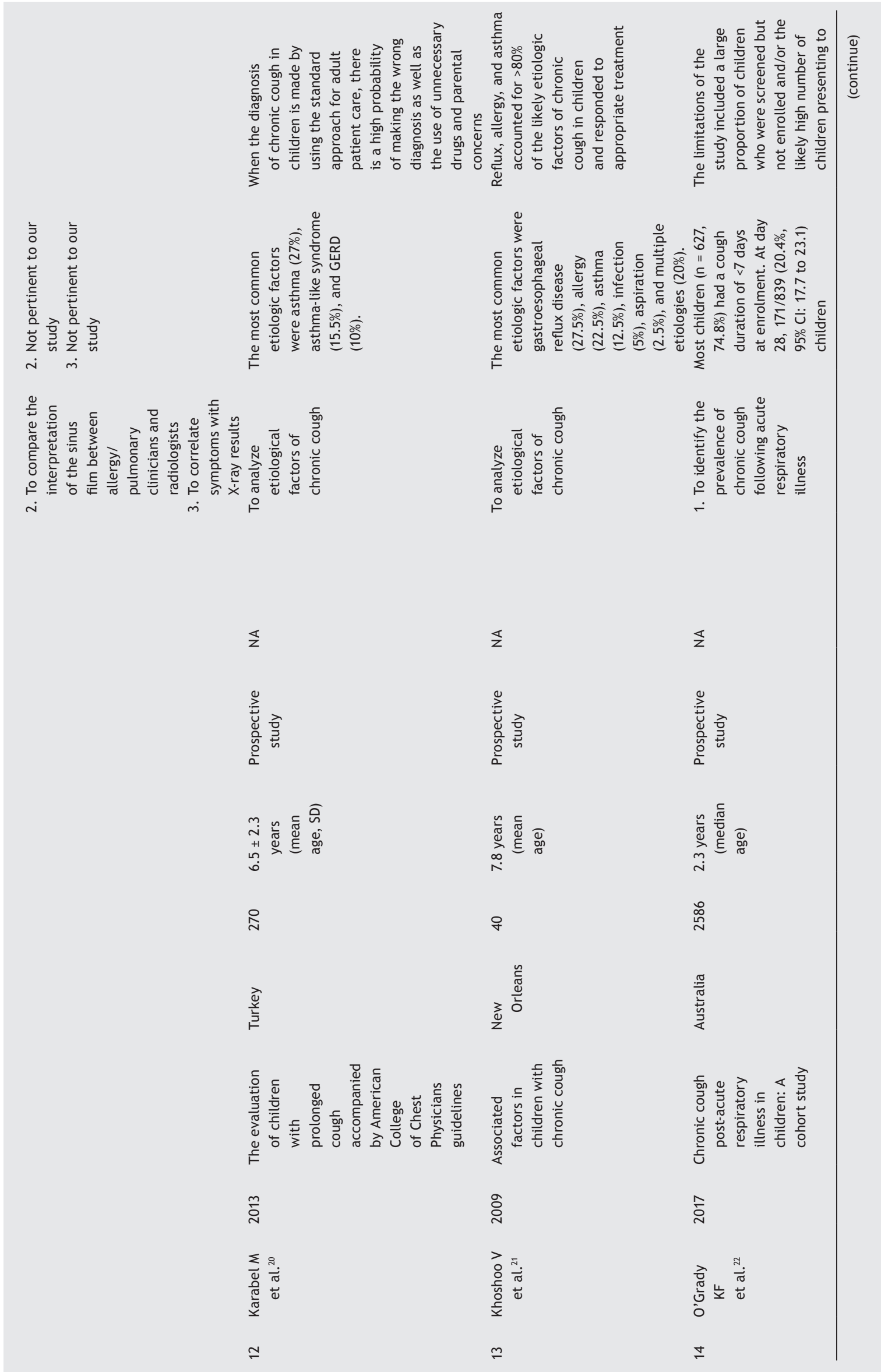




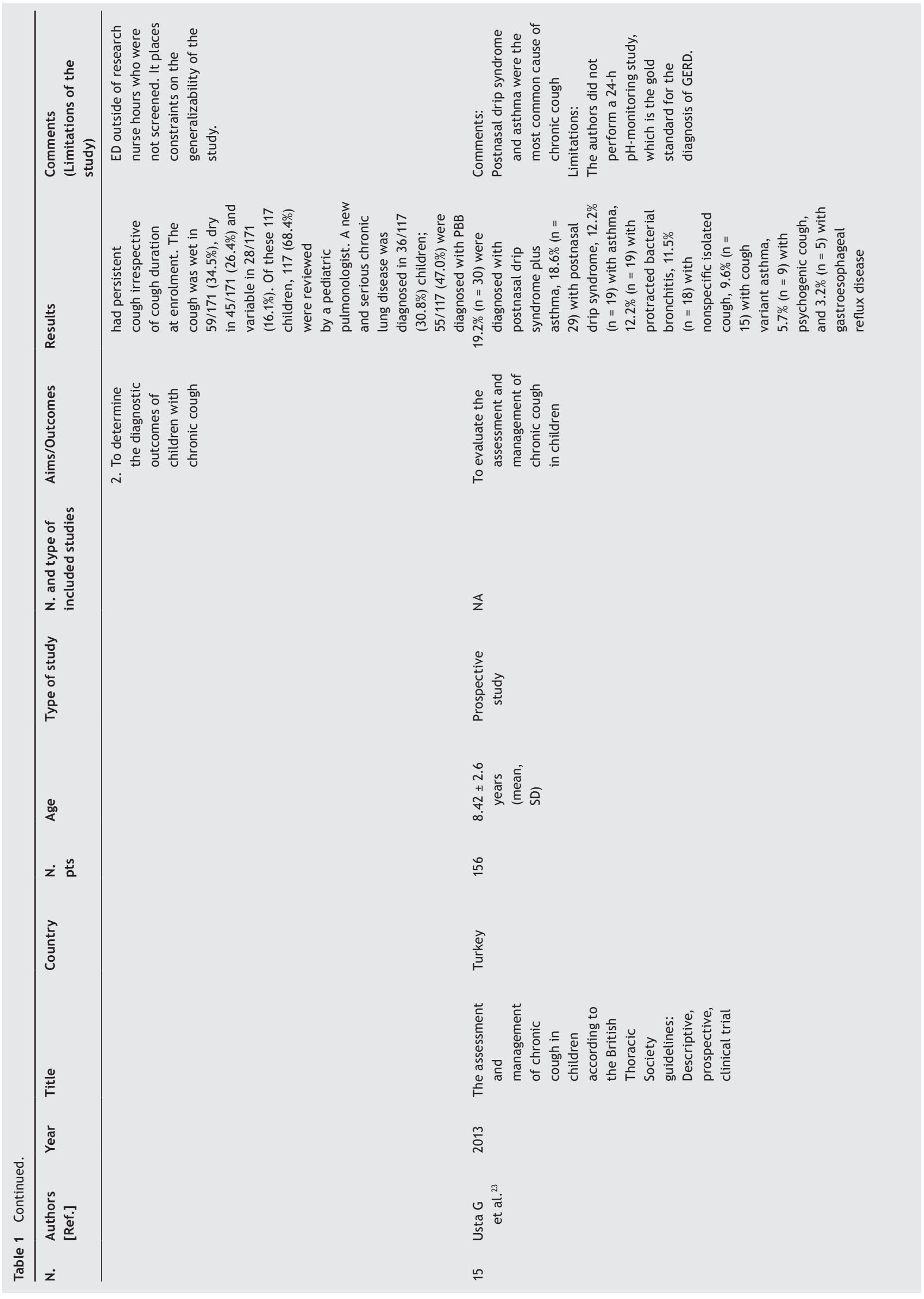



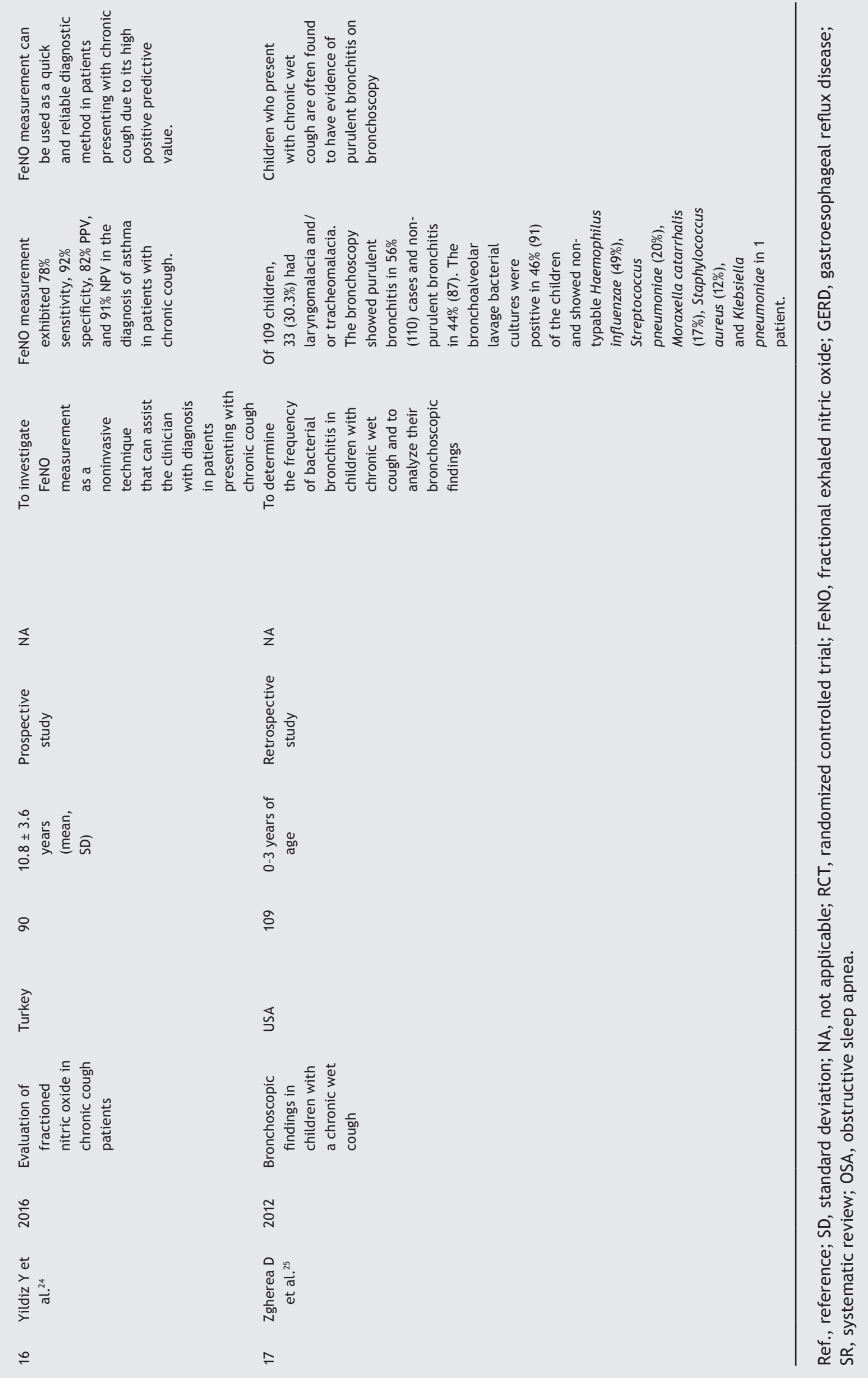
Table 2 List of excluded studies and reasons for exclusion.

\begin{tabular}{|c|c|c|c|c|}
\hline N. & Authors & Year & Title & Reasons for exclusion \\
\hline 1 & $\begin{array}{l}\text { Xepapadaki P } \\
\text { et al. }\end{array}$ & 2010 & $\begin{array}{l}\text { Impulse oscillometry testing in chronic cough in } \\
\text { children. }\end{array}$ & $\begin{array}{l}\text { Focused on impulse oscillometry } \\
\text { testing }\end{array}$ \\
\hline 2 & Anne $S$ et al. & 2016 & $\begin{array}{l}\text { What are management options for chronic cough } \\
\text { in children? }\end{array}$ & Review \\
\hline 3 & Chang $A B$ et al. & 2017 & $\begin{array}{l}\text { Management of children with chronic wet cough } \\
\text { and protracted bacterial bronchitis: CHEST } \\
\text { guideline and expert panel report }\end{array}$ & Guidelines \\
\hline 4 & Greifer $M$ et al. & 2015 & $\begin{array}{l}\text { Pediatric patients with chronic cough and } \\
\text { recurrent croup: the case for a multidisciplinary } \\
\text { approach. }\end{array}$ & $\begin{array}{l}\text { It is not possible to extract data } \\
\text { only on chronic cough }\end{array}$ \\
\hline 5 & $\begin{array}{l}\text { Petrunin Y } \\
\text { et al. }\end{array}$ & 2018 & $\begin{array}{l}\text { Pediatric chronic cough characteristics and } \\
\text { etiology - A retrospective tertiary clinic cohort } \\
\text { study }\end{array}$ & Abstract Meeting \\
\hline 6 & Willis $C$ et al. & 2010 & $\begin{array}{l}\text { Multicentre RCT using a standardized management } \\
\text { algorithm for the treatment of chronic cough in } \\
\text { children }\end{array}$ & Abstract Meeting \\
\hline 7 & $\begin{array}{l}\text { Schmit KM } \\
\text { et al. }\end{array}$ & 2013 & $\begin{array}{l}\text { Evaluating cough assessment tools: A systematic } \\
\text { review }\end{array}$ & $\begin{array}{l}\text { It is not possible to extract } \\
\text { data only on chronic cough. }\end{array}$ \\
\hline 8 & Chang $A B$ et al. & 2006 & $\begin{array}{l}\text { Guidelines for evaluating chronic cough in } \\
\text { pediatrics: ACCP evidence-based clinical } \\
\text { practice guidelines. }\end{array}$ & Guidelines \\
\hline 9 & $\begin{array}{l}\text { Zgherea D } \\
\text { et al. }\end{array}$ & 2012 & $\begin{array}{l}\text { Bronchoscopic findings in children with a chronic } \\
\text { wet cough }\end{array}$ & $\begin{array}{l}\text { Focused on protracted bacterial } \\
\text { bronchitis }\end{array}$ \\
\hline 10 & Zhou J et al. & 2018 & $\begin{array}{l}\text { Values of fractional exhaled nitric oxide for cough- } \\
\text { variant asthma in children with chronic cough }\end{array}$ & $\begin{array}{l}\text { Focused on the diagnosis of cough- } \\
\text { variant asthma in children with } \\
\text { chronic cough }\end{array}$ \\
\hline 11 & Chang $A B$ et al. & 2013 & $\begin{array}{l}\text { A cough algorithm for chronic cough in children: A } \\
\text { multicenter, randomized controlled study }\end{array}$ & Algorithm \\
\hline 12 & $\begin{array}{l}\text { Fracchia MS } \\
\text { et al. }\end{array}$ & 2019 & $\begin{array}{l}\text { The diagnostic role of triple endoscopy in } \\
\text { pediatric patients with chronic cough }\end{array}$ & $\begin{array}{l}\text { It is not possible to extract } \\
\text { data only on the pediatric } \\
\text { population }\end{array}$ \\
\hline 13 & Hare KM et al. & 2015 & $\begin{array}{l}\text { Respiratory bacterial culture from two sequential } \\
\text { bronchoalveolar lavages of the same lobe in } \\
\text { children with chronic cough }\end{array}$ & Not pertinent \\
\hline 14 & $\begin{array}{l}\text { McCallum GB } \\
\text { et al. }\end{array}$ & 2014 & Clinical pathways for chronic cough in children & Review \\
\hline 15 & Yilmaz $O$ et al. & 2014 & Children with a chronic nonspecific isolated cough & Focused on treatment \\
\hline
\end{tabular}

$\mathrm{N}$ : number.

variant asthma (25.9\%), post-infectious cough (22.2\%), GERD (3.7\%), and allergic cough (3.7\%). ${ }^{15}$

In children younger than 2 years of age, protracted bacterial bronchitis (PBB) was more likely found (30.8\%), followed by asthma (27\%), asthma-like syndrome (15.5\%), GERD (10\%), and pneumonia (7.6\%). . $^{12,18,20}$

In children of 5 years old and below, the main etiologies of chronic cough were as follows: asthma (31.8\%), upper airway cough syndrome (37.6\%), cough after infection (18.8\%), GERD (3.5\%), allergic cough $(2.4 \%)$, and unknown causes of cough $(5.9 \%) .{ }^{15,16}$

In the pediatric population aged 5-16 years, GERD, allergy, asthma, infections, and aspiration accounted for $>80 \%$ of the likely etiologic factors of chronic cough. ${ }^{21,23}$ The psychogenic cough was also a common cause of chronic cough in children over 6 years of age (Table 3)..$^{16,23}$

By the characteristics of the cough, it has been reported that asthma, rhinosinusitis, and GERD were the most frequent causes of chronic specific cough, with an incidence of $69.82 \%, 4.6 \%$, and $8.3 \%$, respectively. ${ }^{16}$ The remaining $21 \%$ of patients showed noncystic fibrosis bronchiectasis, cystic fibrosis, bronchiolitis obliterans, tuberculosis, pneumonia, foreign body aspiration, hemosiderosis, and ganglioneuromas. ${ }^{16}$ PBB was the second most common cause of chronic wet cough, with bacterial culture positive for Hemophilus influenzae (43.2\%), Streptococcus pneumoniae $(23.9 \%)$, Moraxella catarrhalis $(23.9 \%)$, Streptococcus pyogenes (6\%), and Staphylococcus aureus (3\%). ${ }^{16}$ 
Table 3 The most common causes of chronic cough in the pediatric population by age.

\begin{tabular}{cl}
\hline Population & Causes \\
\hline Infants & Airway cough syndrome (33.3\%) \\
(5 months to & Cough-variant asthma (25.9\%) \\
1 year of age) & Post-infection cough (22.2\%) \\
& GERD (3.7\%) \\
& Allergic cough (3.7\%) \\
Children & Protracted bacterial bronchitis (30.8\%) \\
(1-2 years of & Asthma (27\%) \\
age) & Asthma-like syndrome (15.5\%) \\
& GERD (10\%) \\
& Pneumonia (7.6\%) \\
Children (2-5 & Asthma (31.8\%) \\
years of age) & Upper airway cough syndrome (37.6\%) \\
& Cough after infection (18.8\%) \\
& GERD (3.5\%) \\
& Allergic cough (2.4\%) \\
& Unknown causes of cough (5.9\%) \\
Children & $>80 \%:$ \\
(5-16 years of & GERD \\
age) & Allergy \\
& Asthma \\
& Infections \\
& Psychogenic cough \\
\hline
\end{tabular}

GERD, gastroesophageal reflux disease.

Patients with a dry cough showed croup, tracheobronchomalacia, psychogenic cough, vascular, and airway abnormalities as the most frequent etiologies. ${ }^{16}$ Mycoplasma pneumoniae and Chlamydia pneumoniae were the most common post-infectious causes in patients with chronic dry cough on normal pulmonary function tests (PFTs) and chest X-rays. ${ }^{10}$

Moreover, two or more associated causative factors were frequently identified in children with a chronic cough in some studies. ${ }^{12,21}$ Specifically, Chang et al. found that $17.6 \%$ of children had more than one diagnosis: tracheomalacia was with PBB $(n=27)$, asthma with PBB $(n=13)$, and $M$. pneumoniae infection $(n=2)$, PBB with asthma $(n=8)$ and aspiration lung disease $(n=4)$, upper airways syndrome with asthma $(n=2)$ and PBB $(n=2)$, an aspiration lung disease with bronchiectasis $(n=1)$, and GERD with PBB $(n=2) .^{12}$

\section{Laboratory and instrumental findings}

Currently, the clinical history and cough characteristics have been adopted as criteria to determine the diagnostic workup of chronic cough.

In their prospective study, Chang et al..$^{13}$ enrolled 326 children newly referred for chronic cough and evaluated data on specific cough pointers (Boxes 1 and 2). They showed that the presence of a specific cough pointer indicating a cause of chronic cough had a sensitivity of $1.0(95 \%$ confidence interval $[\mathrm{Cl}]: 0.98-1.0)$, specificity of $0.95(95 \%$
Box 1 List of systemic and pulmonary cough pointers.

\begin{tabular}{|c|c|}
\hline $\begin{array}{l}\text { Systemic* cough } \\
\text { pointers }\end{array}$ & Pulmonary* cough pointers \\
\hline Cardiac abnormalities & Chest pain \\
\hline Digital clubbing & $\begin{array}{l}\text { Daily moist or productive } \\
\text { cough }\end{array}$ \\
\hline Failure to thrive & Hemoptysis \\
\hline $\begin{array}{l}\text { Medications or drugs } \\
\text { associated with } \\
\text { chronic cough }\end{array}$ & $\begin{array}{l}\text { Abnormal cough characteristics } \\
\text { and/or auscultatory findings }\end{array}$ \\
\hline $\begin{array}{l}\text { Neurodevelopmental } \\
\text { abnormality }\end{array}$ & Recurrent pneumonia \\
\hline Fever & Hypoxia/cyanosis \\
\hline Immunodeficiency & $\begin{array}{l}\text { History of the previous lung } \\
\text { disease or predisposing causes }\end{array}$ \\
\hline Feeding difficulties & $\begin{array}{l}\text { Exertional dyspnea or dyspnea at } \\
\text { rest or tachypnea }\end{array}$ \\
\hline \multirow[t]{2}{*}{ History of contacts } & Chest wall deformity \\
\hline & $\begin{array}{l}\text { Chest radiograph or pulmonary } \\
\text { function test Abnormalities }\end{array}$ \\
\hline
\end{tabular}

$\mathrm{Cl}$ : 0.82-0.99), positive predictive value (PV) of $0.99(95 \%$ Cl: 0.97-1.0), negative PV of 1.0 (95\% Cl: 0.89-1.0), positive likelihood ratio (LR) of 20 (95\% Cl: 5.18-77.21), and negative LR of 0 (95\% Cl: $0-0.03) .{ }^{13}$ Thus, those authors concluded that children with chronic cough without any cough pointers could be safely managed using the watchful waiting approach, while, in the presence of any cough pointers, children would benefit from further investigations, with an odds ratio (OR) of 5.28 (95\% Cl: 1.23-22.73)..$^{13}$

When specific cough pointers (systemic and/or pulmonary cough pointers (Boxes 1 and 2) are present (high-quality evidence) and/or cough does not resolve within a specific time frame (ranging from 1 to $>6$ months) following the use of antibiotics (moderate-quality evidence), investigations should be undertaken to determine if an underlying lung disease or other diseases are present. ${ }^{9}$

In this regard, the most frequently performed investigations were fiberoptic bronchoscopy (FB) with bronchoalveolar lavage (BAL) and chest computed tomography (CT) scans or assessment of immunity; however, the chest radiograph remains the first line of instrumental investigation to perform in children with chronic cough. The FB was reporting up to 74\% airway abnormalities, ${ }^{9}$ purulent bronchitis in $56 \%$ of cases, and laryngomalacia and/or tracheomalacia in $30.3 \%$ of cases. ${ }^{25} \mathrm{BAL}$, considered as the "gold standard" to identify lower airway infections, was used to detecting Haemophilus influenza (49\%), S. pneumoniae (20\%), M. catarrhalis (17\%), and S. aureus (12\%) as the most common bacteria. ${ }^{25}$ Chest CT scans were also reported as positive, and poor radiologic outcomes and structural airway abnormalities were more frequently occurring with longer cough duration. ${ }^{9}$

A retrospective analysis, enrolling 58 pediatric patients younger than 18 years, revealed that flexible laryngoscopy, chest radiograph, and CT scan of the sinuses were also commonly performed in patients with chronic cough. Flexible laryngoscopy appeared useful both in the diagnosis 
Box 2 Cough pointers and related underlying diseases.

\begin{tabular}{|c|c|}
\hline Cough pointers & Underlying disease \\
\hline Wheezing episodes & Asthma \\
\hline \multicolumn{2}{|l|}{ Atopy } \\
\hline \multicolumn{2}{|l|}{ Dyspnea on exertion } \\
\hline Allergic salute & Allergic rhinitis \\
\hline Clearing throat & Postnasal drip \\
\hline Wet/productive cough & Cystic fibrosis \\
\hline \multirow[t]{2}{*}{ Persistent/recurrent endobronchial infections } & Primary ciliary dyskinesia \\
\hline & Protracted bacterial bronchitis \\
\hline Choking with food & Recurrent aspiration \\
\hline Penetration syndrome & Foreign body inhalation \\
\hline Brassy or barking cough & Tracheo/bronchomalacia, airways compression \\
\hline "Bizarre" cough & Psychogenic cough \\
\hline Dry cough, breathless, restrictive spirometry & Interstitial lung disease \\
\hline Progressive cough, weight loss, fevers & $\begin{array}{l}\text { Exertional dyspnea or dyspnea at rest or } \\
\text { tachypnea }\end{array}$ \\
\hline History of contacts & Tuberculosis \\
\hline \multirow[t]{2}{*}{ Hemoptysis } & Interstitial lung disease \\
\hline & Bronchiectasis \\
\hline Chest deformity & Chronic lung disease \\
\hline \multicolumn{2}{|l|}{ Auscultatory findings } \\
\hline Symptoms worsening after feeding or when lying down & GERD \\
\hline Digital clubbing & Systemic immunodeficiency \\
\hline Neonatal onset & Congenital abnormalities \\
\hline $\begin{array}{l}\text { Positive history for prematurity and neonatal respiratory } \\
\text { intensive care }\end{array}$ & Bronchopulmonary dysplasia \\
\hline Cough productive of casts & Plastic bronchitis or asthma \\
\hline Chronic wet cough in mornings only & Suppurative lung disease \\
\hline
\end{tabular}

of upper respiratory tract affections and GERD. ${ }^{19}$ A chest radiograph was ordered for patients for whom the treatment failed, resulting in positive in most cases. ${ }^{19}$ OR for abnormal chest radiograph findings appeared significant for the diagnosis of $\mathrm{PBB}$ and pneumonia, showing a sensitivity of $0.20(95 \% \mathrm{Cl}: 0.16-0.26)$, specificity of $1.0(95 \% \mathrm{Cl}$ : 0.89-1.00), positive PV of 1.00 (95\% Cl: 0.92-1.0), negative PV of 0.15 (95\% Cl: 0.11-0.2), positive LR infinity, and negative LR of $0.8(95 \% \mathrm{Cl}: 0.75-0.85)$ for the specific cough all-causes. ${ }^{13} \mathrm{CT}$ scan of the sinuses was positive in patients with chronic nasal symptoms and chronic cough; X-ray of the sinuses was able to detect sinus abnormalities in more than half of the cases. ${ }^{19}$

Although spirometry (pre- and post-ß2-agonists) is commonly performed in daily practice, literature data are lacking regarding its use in the pediatric population with chronic cough. ${ }^{9-12,14-23}$ Nevertheless, in their multicenter study, the authors revealed that spirometry showed a sensitivity of 0.03 (95\% Cl: 0.01-0.06), specificity of 1.0 (95\% Cl: 0.89-1.00), positive PV of 1.00 (95\% Cl: 0.60-1.0), negative PV of 0.13 (95\% Cl: 0.09-0.17), positive LR infinity, and negative LR of 0.97 (95\% Cl: 0.95-0.95) for the specific cough all-causes. ${ }^{13}$

Finally, only one of the studies included in our systematic review investigated the diagnostic role of fractional exhaled nitric oxide (FeNO) in 90 children, aged 6-17 years, with chronic cough. ${ }^{24}$ By assuming 24 part per billion (ppb) and above values for FeNO positivity, Yildiz et al. revealed that FeNO showed a sensitivity of 0.78 , a specificity of 0.92 , a positive $P V$ of 0.81 , and a negative PV of 0.91 , supporting its use as a quick and reliable diagnostic method in patients with chronic cough. ${ }^{24}$

\section{Discussion}

Chronic cough, defined as the presence of daily cough for more than 4 weeks in duration, is hugely complicated to evaluate, and very often, the underlying disease remains not diagnosed, misdiagnosed, and/or inappropriately treated. After conducting an updated systematic review about the management of chronic cough in children and adolescents, the SIAIP proposed a diagnostic algorithm to offer a practical guide for the pediatrician to improve management and clinical outcomes (Figure 2).

The initial assessment of chronic cough includes a detailed history and physical examination. First, obtaining a comprehensive clinical history allows the pediatrician to understand whether the patient is affected by a chronic 


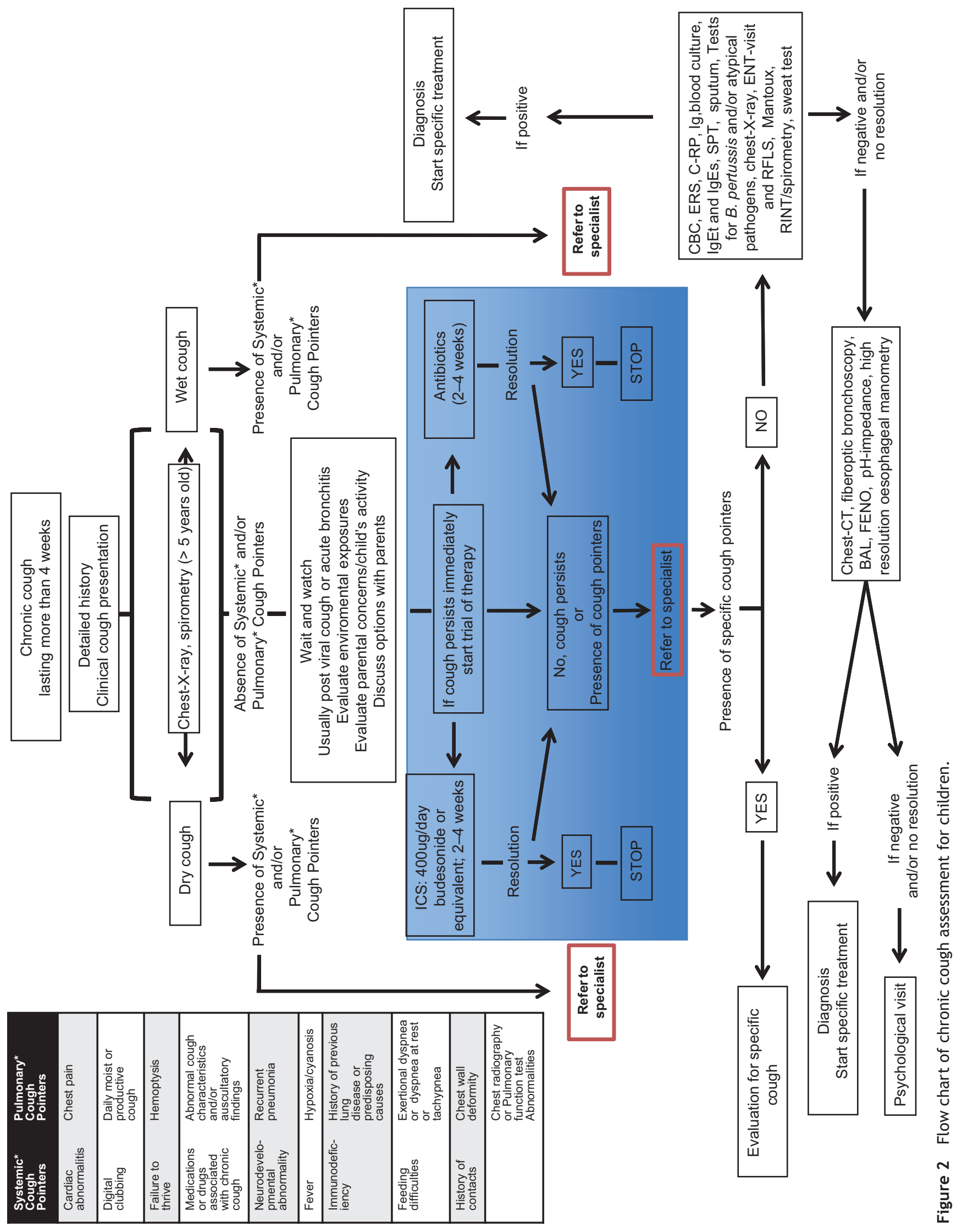


cough. The definition of chronic cough is nebulous, and it varies widely among the studies..$^{9-24}$ In this study, we adopted a period longer than 4 weeks as a cutoff period to define the cough as chronic. This prolonged observation period allows observing a spontaneous cough resolution for $20 \%$ of otherwise healthy children, according to the postinfectious etiology in many children with chronic cough. ${ }^{5,12}$ Furthermore, during childhood, numerous anatomical and physiological maturation processes in the respiratory tract, nervous system, and immune response naturally occur and positively contribute to spontaneous cough resolution. ${ }^{27,28}$

A detailed clinical history also permits to guide the workup for a specific diagnosis by the age of the child, the age at symptom onset, and the presence or absence of systemic and/or pulmonary "red flags" (Boxes 1 and 2). If the cough starts early after birth, spontaneously or acquired after prior intubation, trauma, infection, or inflammation, genetic disorders (cystic fibrosis, primary ciliary dyskinesia [Box 3] ${ }^{29}$ ); immunodeficiencies; congenital anomalies (pulmonary, cardiac, and vascular abnormalities); pulmonary disorders (tracheobronchomalacia and surfactant dysfunction); and neuromuscular diseases must be clinically suspected. ${ }^{6}$ A sudden onset, a history of choking, followed by prolonged cough in a healthy child between 0 and 3 years of age, may suggest foreign body aspiration. ${ }^{6,30}$ Due to the enhanced responsiveness of the cough receptors, prolonged ciliary repair, and increased mucus secretion following infections, $28-57 \%$ of preschool children with a previous positive history of pneumonia suffer from post-infectious cough, which is generally self-limited. ${ }^{31-35}$ The history of post-tussive vomiting and nausea, paroxysmal cough, and/ or inspiratory whoop suggests that chronic cough can be caused by Bordetella pertussis. ${ }^{32}$ The "allergic salute" and the "throat-clearing" type of cough can suggest the presence of postnasal drip, although the evidence of a relationship between postnasal drip and irritation of the larynx is lacking. ${ }^{36}$

Attention must be paid to the occurrence of symptoms of a dry, noisy, and barky cough occurring only during the night, which in many cases suggests a functional breathing disorder (somatic or tic cough). Although some guidelines suggest that the presence or absence of nighttime cough with barking or honking characteristics should not be used to diagnose or exclude a dysfunctional cough syndrome, undoubtedly, the sudden occurrence of cough symptoms in an adolescent exclusively during the night remains suggestive of somatic or tic cough. ${ }^{37}$

Exposure to pollution, allergen, and smoke may be a reason for chronic cough. ${ }^{6}$ The presence of comorbidities and the use of drugs must also be investigated; interstitial lung diseases can occur in patients who experience autoimmune or neoplastic diseases and/or undergo cytotoxic drugs or radiation treatment. ${ }^{5}$ Finally, the impact of cough on patients' quality of life should also be recorded by administering validated questionnaires (e.g., Parent Cough-Specific QOL Questionnaire [PC-QOL], generic child: Pediatric QOL Inventory 4.0 [PedsQL], parent QOL questionnaires [SF-12], visual analog score [VAS], and verbal category descriptive [VCD] score), which might be helpful to stage cough and report changes in clinical symptoms. ${ }^{34}$

Differentiating between a dry and wet cough may detect the presence or absence of cough pointers (Boxes 1 and 2) that would point to an underlying disease. At this point, a chest radiograph and, when age-appropriate, spirometry should be undertaken in the first-line assessment of children with chronic cough, since the presence of abnormalities implies the presence of disease. ${ }^{26}$

In the absence of cough pointers, a short-term of highdose $(400 \mu \mathrm{g} / \mathrm{d})$ inhaled corticosteroids (ICS), budesonide or beclomethasone, trial (2-4 weeks) in children with a chronic dry cough could provide a modest but significant benefit in cough symptoms. ${ }^{6,35}$ Among the guidelines on chronic cough, a defined period of ICS trial is not provided, ranging from at least 2 to 12 weeks. ${ }^{5,6,35}$ Probably, the authors aimed to differentiate the responders to a 2-week trial from the non-responders, requiring a more extended treatment period and eventually developing asthma. 5,6,35,36 Specifically, if asthma therapy is warranted, the use of a $400 \mu \mathrm{g} / \mathrm{d}$ equivalent dose of budesonide (or beclomethasone) up to 2 weeks has been suggested, and a clinical reassessment after 2-3 weeks is also recommended. Cough

Box 3 Seven-point questionnaire-based prediction tool (PrImary CiliARy DyskinesiA Rule: PICADAR) to predict the likelihood of primary ciliary dyskinesia (PCD). ${ }^{29}$

\begin{tabular}{|c|c|c|}
\hline \multicolumn{3}{|l|}{ PICADAR } \\
\hline Does the patient have a daily wet cough that started in early childhood? & \multicolumn{2}{|c|}{$\begin{array}{l}\text { Yes - complete PICADAR } \\
\text { No - STOP. PICADAR is not designed } \\
\text { for patients without a wet cough }\end{array}$} \\
\hline Was the patient born pre-term or full-term? & Term & 2 \\
\hline $\begin{array}{l}\text { Did the patient experience chest symptoms in the neonatal period (e.g., tachypnoea, } \\
\text { cough, and pneumonia)? }\end{array}$ & Yes & 2 \\
\hline Was the patient admitted to a neonatal unit? & Yes & 2 \\
\hline Does the patient have a situs abnormality (situs viscerum inversus or heterotaxy)? & Yes & 4 \\
\hline Does the patient have a congenital heart defect? & Yes & 2 \\
\hline Does the patient have persistent perennial rhinitis? & Yes & 1 \\
\hline \multirow{2}{*}{$\begin{array}{l}\text { Does the patient experience chronic ear or hearing symptoms (e.g., glue ear, serous } \\
\text { otitis media, hearing loss, ear perforation)? }\end{array}$} & Yes & 1 \\
\hline & \multicolumn{2}{|c|}{ Total score $=$} \\
\hline
\end{tabular}


that is unresponsive to ICS treatment should not be treated with increased doses of ICSs. On the other hand, the resolution of cough with ICS therapy does not necessarily support a diagnosis of asthma, as an asthma-like transient clinical syndrome may occur post-upper respiratory tract infections (URTIs); thus, the patient should be reevaluated after treatment is stopped. ${ }^{26,38}$

A 2-4-week course of appropriate oral antibiotic guarantees a high response rate $(>75 \%)$ in the resolution of chronic wet cough. 6,39 The efficacy of antibiotics in chronic wet cough treatment was assessed by three RCTs, showing a clear benefit. ${ }^{9}$ However, in their systematic review, Chang et al. ${ }^{39}$ found lower-level evidence about the type and duration of antibiotics required. Amoxicillinclavulanate appeared the most commonly used antibiotic, followed by clarithromycin, erythromycin, and cefaclor. Macrolide antibiotics are generally administered in children with pertussis. ${ }^{36}$ Other antibiotics were rarely used in chronic cough treatment. ${ }^{40}$ The duration of treatment ranged from 1 to 8 weeks: a 2-week course was sufficient, but when a chronic wet cough persists after 2 weeks of antibiotic treatment, an additional treatment of 2 weeks is suggested, especially if a PBB is suspected (Box 4). ${ }^{26}$ If a PBB diagnosis is confirmed, the patient should undergo bronchoalveolar lavage or sputum to differentiate "PBB without lower airway bacteria confirmation" from "PBB with lower airway bacteria confirmation," requiring a specific therapeutic regimen. ${ }^{26}$ Children not reporting clinical improvement after 4 weeks of antibiotic treatment showed an increased risk of CT scan-diagnosed bronchiectasis that can occur with several chronic lung diseases, such as cystic fibrosis, primary ciliary dyskinesia, and also with PBB (adjusted OR: 5.9 [95\% Cl: 1.2-28.5]).9,41 Therefore, further investigations such as chest CT and flexible bronchoscopy should be performed to assess for an underlying disease. ${ }^{42}$

In the presence of cough pointers or persistence of cough, a referral from a primary care physician to a specialist is suggested. If systemic or pulmonary cough pointers are detected (Boxes 1 and 2), further diagnostic and therapeutic management will be guided by the clinical features and etiologic hypothesis. If no specific pointers are reported, we suggest that further investigations need to be undertaken and targeted toward the patient.

Box 4 Diagnostic criteria for the clinical diagnosis of protracted bacterial bronchitis (PBB).*

\begin{tabular}{l} 
Diagnostic criteria \\
\hline 1. Presence of continuous chronic ( $>4$ weeks' duration) \\
wet or productive cough \\
2. Absence of symptoms or signs (i.e., specific cough \\
pointers) suggestive of other causes of wet or \\
productive cough \\
3. Cough resolved following a 2-4-week course of an \\
appropriate oral antibiotic
\end{tabular}

*All three of the above-reported criteria must be fulfilled. ${ }^{36}$
Complete blood count, erythrocyte sedimentation rate (ESR), C-reactive protein, and first-step immunity evaluation (immunoglobulin [lg]A, IgM, and IgG) should be performed for cases with the most likely causes of chronic cough. ${ }^{38}$ Viruses such as Cytomegalovirus, Respiratory Syncytial Virus, and Adenovirus, or atypical microorganisms, including $M$. pneumoniae, C. pneumoniae, $B$. pertussis or Parapertussis can result in chronic cough. Accordingly, blood culture, serology, or polymerase chain reaction on nasopharyngeal secretions and sputum should be attempted in case of suspected infectious causes. In settings with high tuberculosis exposure or abnormal X-ray findings, appropriate tests for Mycobacterium tuberculosis infection are required. ${ }^{39,40}$

As conflicting findings about the relationship between chronic cough and atopy are reported, in the absence of symptoms and signs of allergy, testing for sensitization, such as skin prick test, total, and specific lgE, should not be performed. ${ }^{5,6}$ It has been reported that all these tests are unlikely to predict the patient's response to treatment, and cough sensitivity in atopic children is not elevated. ${ }^{26}$

Children with a chronic wet cough should also be investigated to document the underlying causes such as cystic fibrosis. ${ }^{5}$

In patients with chronic cough reporting recurrent symptoms suggestive of sinus and nasal inflammation, an otorhinolaryngological visit, nasal endoscopy, and sinus CT scan may be performed. ${ }^{39,40}$ On the one hand, nasal discharge and chronic cough are symptoms commonly reported in a child affected by chronic sinusitis, while, on the other hand, the evidence does not support the causeeffect relationship and reveal discordance between clinical symptoms and diagnostic tests and, consequently, the nonappropriateness of treatment options. . $^{5,42,43}$

Airways resistance determined by the interrupter technique and spirometry pre- and post-ß2-agonists test is useful in detecting isolated cough associated with airway hyperresponsiveness and asthma. ${ }^{6}$

A child with a chronic cough should undergo a chest radiograph. However, in the presence of chronic cough refractory to treatment in a child without a precise diagnosis, despite a normal chest X-ray, a chest CT scan should be attempted to evaluate small airway structural integrity and document lung diseases not visible on chest radiograph and, potentially, requiring FB. ${ }^{5,6}$ Other indications for FB in children affected by chronic cough are localized radiology changes, suspicion of inhaled foreign body, aspiration lung disease, or the need to perform clearance, lavage, and microbiological investigations. ${ }^{5}$ Purulent bronchitis, laryngomalacia, and tracheomalacia are frequently detected in children with a chronic wet cough by performing FB. ${ }^{25}$ Although BAL findings are widely reported and interpreted by the study authors as being consistent with infections, only a few studies have performed quantitative bacteriologic testing. Among these, prospective and retrospective studies have found clinically significant levels of both respiratory bacteria density ( $>10^{4}$ colony forming units $/ \mathrm{mL}$ ) and neutrophils assessing a persistent airways infection in children with chronic wet cough. 9,40,44

The clinical usefulness of FeNO measurement in aiding diagnosis in patients with chronic cough has not yet been systematically evaluated, due to its high positive predictive 
value. However, we suggest that FeNO can be used as the second level of investigation in patients presenting with chronic cough-variant asthma. , $^{4,45,46}$

Despite claims to the contrary, gastroesophageal reflux appears to be a less frequent and doubtful cause of chronic cough in the pediatric population. ${ }^{5}$ Although there is a high incidence of esophageal dysmotility in patients with chronic cough, it is more likely that reflux is the effect and not the cause of chronic cough. ${ }^{5}$ For children with a chronic cough in the absence of underlying lung disease, the treatment for GERD is not suggested when clinical features of GER, such as recurrent regurgitation, dystonic neck posturing in infants, or heartburn/epigastric pain in older children, are absent. The patient should be treated following evidence-based GERD-specific guidelines ${ }^{47}$; if an acid-suppressive therapy is required, it should be administered for 4-8 weeks and, after treatment suspension, a clinical reassessment is recommended. ${ }^{26}$ Esophageal impedance 24-hour $\mathrm{pH}$ monitoring is the most sensitive tool for assessing all types of gastroesophageal reflux; in children aged less than 2 years, cough episodes were frequently preceded by weak acid reflux. ${ }^{48}$ Other diagnoses (Box 5 ) require further

Box 5 Symptoms that may be associated with gastroesophageal reflux disease (GERD) and 'Red Flag' symptoms are suggestive of disorders other than GERD in infants and children $0-18$ years old. ${ }^{47}$

\begin{tabular}{|c|c|}
\hline $\begin{array}{l}\text { Symptoms associated with } \\
\text { GERD }\end{array}$ & Red Flags symptoms \\
\hline $\begin{array}{l}\text { General: } \\
\text { 1. Irritability } \\
\text { 2. Failure to thrive } \\
\text { 3. Feeding refusal } \\
\text { 4. Dystonic neck posturing }\end{array}$ & $\begin{array}{l}\text { General: } \\
\text { 1. Weight loss } \\
\text { 2. Lethargy } \\
\text { 3. Fever } \\
\text { 4. Excessive irritability/ } \\
\text { pain } \\
\text { 5. Dysuria } \\
\text { 6. Onset of regurgitation/ } \\
\text { vomiting >6 months or } \\
\text { increasing/persisting } \\
>12-18 \text { months of age }\end{array}$ \\
\hline $\begin{array}{l}\text { Gastrointestinal: } \\
\text { 1. Recurrent regurgitation } \\
\text { with/without vomiting in } \\
\text { the older child } \\
\text { 2. Heartburn/chest pain } \\
\text { 3. Epigastric pain } \\
\text { 4. Hematemesis } \\
\text { 5. Dysphagia/odynophagia }\end{array}$ & $\begin{array}{l}\text { Neurological: } \\
\text { 1. Bulging fontanel/ } \\
\text { rapidly increasing head } \\
\text { circumference } \\
\text { 2. Seizures } \\
\text { 3. Macro/ } \\
\text { microcephaly }\end{array}$ \\
\hline $\begin{array}{l}\text { Airway: } \\
\text { 1. Wheezing } \\
\text { 2. Stridor } \\
\text { 3. Cough } \\
\text { 4. Hoarseness }\end{array}$ & $\begin{array}{l}\text { Gastrointestinal: } \\
\text { 1. Persistent forceful } \\
\text { vomiting } \\
\text { 2. Nocturnal vomiting } \\
\text { 3. Bilious vomiting } \\
\text { 4. Hematemesis } \\
\text { 5. Chronic diarrhea } \\
\text { 6. Rectal bleeding } \\
\text { 7. Abdominal distension }\end{array}$ \\
\hline
\end{tabular}

investigations such as laboratory tests, contrast imaging, upper gastrointestinal endoscopy, and high-resolution esophageal manometry, depending on presenting symptoms..$^{5,47,48}$ Recently, a multidisciplinary "triple" endoscopy has been proposed as a useful investigative tool for patients with recalcitrant aero-digestive complaints like chronic cough. ${ }^{49}$ In their retrospective study, the authors reported that a rigid upper airway evaluation, a flexible bronchoscopy, bronchoalveolar lavage, and an endoscopy with biopsies performed by a gastroenterologist could provide more than one diagnosis, usually missed by one single procedure. ${ }^{49}$

Finally, if an extensive evaluation fails to clarify the etiology of chronic cough, somatic cough disorder such as habit cough, tic cough, and a psychogenic cough must be hypothesized, and counseling or referral to a psychologist/ psychiatrist has been suggested in the diagnostic management. 5,6 Although the habit cough is featured by a repetitive cough with barking or honking characteristics, and absence of symptom once asleep, these characteristics should be not used as a marker of habit cough. Similar to tics, suppressibility, distractibility, suggestibility, variability, and the presence of a premonitory sensation should be taken into consideration. Moreover, by the DSM- 5 classification of diseases, the authors suggest substituting the diagnostic term "tic cough" with "habit cough" and "somatic cough" with "psychogenic cough". ${ }^{26}$

\section{Limitation of the study}

We developed this systematic review using a rigorous research method. However, we cannot exclude that some studies have not been included in the present manuscript.

\section{Conclusions}

In summary, we elaborated a comprehensive algorithm to guide a primary care approach to pediatric patients with chronic cough.

Several algorithms for the management of chronic cough have been adopted and validated in clinical practice $\mathrm{e}^{5,6,16,20,35}$; however, unlike the latter, we developed an algorithm focused on the pediatric age, and, also, in accordance with the Italian National Health System, which always follows the child from birth to all lifelong. Based on our findings, children with chronic cough without cough pointers can be safely managed, initially, using the watchful waiting approach and, successively, starting empirical treatment based on cough characteristics. Unlike other algorithms that suggest laboratory and instrumental investigations as a first step, ${ }^{5,6,16,20,35}$ we highlighted the importance of a "wait and see" approach, consisting of parental reassurance and close clinical observation, also due to interprofessional collaboration and communication between general practitioners and specialists that guarantee better patient management, appropriate prescription behavior, and improved patient outcome. Moreover, the neonatal screening program, provided by the Italian National Health System, which intercepts several diseases precociously allowing to treat 
them in a very early stage, helps and supports a "wait and see" approach.

Conversely, in the presence of cough pointers or persistence of cough, the patient should be tested and treated by a specialist. Further investigations and treatments will be based on cough etiology, aiming to intercept the underlying disease, prevent potentially irreversible tissue damage, improve the general health of patients affected by chronic cough, as well as the quality of life of patients and its family.

Further high-quality RCTs are needed to validate this algorithm's performance in real-life clinical practice.

\section{Declarations}

Ethical Approval and Consent to participate: not applicable

Consent for publication: not applicable

Availability of supporting data: not applicable.

Competing interests: The authors declare that they have no competing interests.

Funding: The publication of this article has been supported by the Italian Society of Pediatric Allergy and Immunology.

Authors' contributions: This study was a collaboration between all authors.

Acknowledgments: not applicable.

\section{References}

1. Fontana GA. Before we get started: What is a cough? Lung. 2008;186:S3-6. https://doi.org/10.1007/s00408-007-9036-8

2. McGovern AE, Short KR, Kywe Moe AA, Mazzone SB. Translational review: Neuroimmune mechanisms in cough and emerging therapeutic targets. J Allergy Clin Immunol. 2018;142(5):1392-402. https://doi.org/10.1016/j.jaci.2018.09.004

3. Canning BJ, Chang AB, Bolser DC, Smith JA, Mazzone SB, McGarvey L, et al. Anatomy and neurophysiology of cough: CHEST Guideline and Expert Panel report. Chest. 2014;146(6):1633-48. https://doi.org/10.1378/chest.14-1481

4. Chung KF. The clinical and pathophysiological challenge of cough. In: Chung KF, Widdicombe JG, Boushey HA, editors. Cough: Causes, mechanisms, and therapy. Oxford, UK: Blackwell Publishing Ltd; 2003. p. 3-10. https://doi. org/10.1002/9780470755846

5. Chang $A B$, Glomb WB. Guidelines for evaluating chronic cough in pediatrics: ACCP evidence-based clinical practice guidelines. Chest. 2006;129(Suppl 1):260S-83S. https://doi. org/10.1378/chest.129.1_suppl.260S

6. Morice AH, Millqvist E, Bieksiene K, Birring SS, Dicpinigaitis P, Domingo Ribas $\mathrm{C}$, et al. ERS guidelines on the diagnosis and treatment of chronic cough in adults and children. Eur Respir J. 2020; 55(1):1901136. https://doi. org/10.1183/13993003.01136-2019

7. Higgins JPT, Green S, editors. Cochrane Handbook for Systematic Reviews of Interventions Version 5.1.0. The Cochrane Collaboration; 2011. www.cochrane-handbook.org

8. Liberati A, Altman DG, Tetzlaff J, Mulrow C, Gøtzsche PC, loannidis JPA, et al. The PRISMA statement for reporting systematic reviews and meta-analyses of studies that evaluate health care interventions: Explanation and elaboration. J Clin Epidemiol. 2009;62:e1-34. https://doi.org/10.1016/j. jclinepi.2009.06.006
9. Chang $\mathrm{AB}$, Oppenheimer JJ, Weinberger $\mathrm{M}$, Rubin BK, Irwin RS. Children with chronic wet or productive cough Treatment and investigations: A systematic review. Chest. 2016;149(1):120-42. https://doi.org/10.1378/chest.15-2065

10. Asilsoy S, Bayram E, Can D. Seroprevalence of chlamydia pneumoniae and mycoplasma pneumoniae in children with chronic cough. Asthma Allergy Immunol. 2015;13:3.

11. Cash H, Trosman S, Abelson T, Yellon R, Anne S. Chronic cough in children. JAMA Otolaryngol Head Neck Surg. 2015;141(5):41723. https://doi.org/10.1001/jamaoto.2015.0257

12. Chang $A B$, Robertson CF, Van Asperen PP, Glasgow NJ, Mellis CM, Masters IB, et al. A multicenter study on chronic cough in children: Burden and etiologies based on a standardized management pathway. Chest. 2012;142(4):943-50. https://doi.org/10.1378/chest.11-2725

13. Chang $A B$, Van Asperen PP, Glasgow N, Robertson CF, Mellis CM, Masters IB, et al. Children with chronic cough: When is watchful waiting appropriate? Development of likelihood ratios for assessing children with chronic cough. Chest. 2015;147(3):745-53. https://doi.org/10.1378/chest.14-2155

14. Chang AB, Oppenheimer JJ, Weinberger M, Weir K, Rubin BK, Irwin RS. Use of management pathways or algorithms in children with chronic cough: Systematic reviews. Chest. 2016;149(1):106-19. https://doi.org/10.1378/chest.15-1403

15. Chen X, Peng WS, Wang L. Etiology analysis of non-specific chronic cough in children of 5 years and younger. Medicine (Baltimore). 2019;98(3):e13910. https://doi.org/10.1097/ MD.0000000000013910

16. Gedik AH, Cakir E, Torun E, Demir AD, Kucukkoc $M$, Erenberk U, et al. Evaluation of 563 children with chronic cough accompanied by a new clinical algorithm. Ital J Pediatr. 2015;41:73. https://doi.org/10.1186/s13052-015-0180-0

17. Hare KM, Chang AB, Smith-Vaughan HC, Bauert PA, Spain B, Beissbarth J, et al. Do combine upper airway cultures identify lower airway infections in children with chronic cough? Pediatr Pulmonol. 2019;54(6):907-13. https://doi.org/10.1002/ ppul.24336

18. Ilarslan NEC, Gunay F, Haskologlu ZS, Bal SK, Tezcaner ZC, Kirsaclioglu $\mathrm{CT}$, et al. Evaluation of children with chronic cough including obstructive sleep apnea: A single-center experience. Eur J Pediatr. 2019;178(2):189-97. https://doi. org/10.1007/s00431-018-3276-x

19. Wilson NW, Hogan MB, Harper CB, Peele K, Budhecha S, Loffredo $\mathrm{V}$, et al. Sinusitis and chronic cough in children. J Asthma Allergy. 2012;5:27-32. https://doi.org/10.2147/JAA.S31874

20. Karabel M, Kelekçi S, Karabel D, Gürkan MF. The evaluation of children with prolonged cough accompanied by American College of Chest Physicians guidelines. Clin Respir J. 2014;8(2):152-9. https://doi.org/10.1111/crj.12052

21. Khoshoo V, Edell D, Mohnot S, Haydel R Jr, Saturno E, Kobernick A. Associated factors in children with chronic cough. Chest. 2009;136(3):811-15. https://doi.org/10.1378/ chest.09-0649

22. O'Grady KF, Drescher BJ, Goyal V, Phillips N, Acworth J, Marchant JM, et al. Chronic cough post-acute respiratory illness in children: A cohort study. Arch Dis Child. 2017;102(11):10448. https://doi.org/10.1136/archdischild-2017-312848

23. Usta Guc B, Asilsoy S, Dur Yilmaz C. The assessment and management of chronic cough in children according to the British Thoracic Society guidelines: A descriptive, prospective, clinical trial. Clin Respir J. 2014;8(3):330-7. https://doi. org $/ 10.1111 / \mathrm{crj} .12076$

24. Yildiz $Y$, Igde $M$. Evaluation of fractioned nitric oxide in chronic cough patients. Niger J Clin Pract. 2018;21(1):1-6.

25. Zgherea D, Pagala S, Mendiratta M, Marcus MG, Shelov SP, Kazachkov M. Bronchoscopic findings in children with chronic wet cough. Pediatrics. 2012;129(2):e364-9. https://doi. org/10.1542/peds.2011-0805 
26. Chang AB, Oppenheimer JJ, Irwin RS, CHEST Expert Cough Panel. Managing chronic cough as a symptom in children and management algorithms: CHEST guideline and expert panel report. Chest. 2020; 158(1):303-329.

27. Hay $A D$, Wilson $A D$. The natural history of acute cough in children aged 0 to 4 years in primary care: A systematic review. Br J Gen Pract. 2002;52(478):401-9.

28. Kantar A, Bernardini R, Paravati F, Minasi D, Sacco O. Chronic cough in preschool children. Early Hum Dev. 2013;89:S19-24. https://doi.org/10.1016/j.earlhumdev.2013.07.018

29. Behan L, Dimitrov BD, Kuehni CE, Hogg C, Carroll M, Evans HJ, et al. PICADAR: A diagnostic, predictive tool for primary ciliary dyskinesia. Eur Respir J. 2016;47(4):1103-12. https://doi. org/10.1183/13993003.01551-2015

30. Sahin A, Meteroglu F, Eren S, Celik Y. Inhalation of foreign bodies in children: Experience of 22 years. J Trauma Acute Care Surg. 2013;74:658-63. https://doi.org/10.1097/ TA.0b013e3182789520

31. Nadel JA. Mucus hypersecretion and relationship to cough. Pulm Pharmacol Ther. 2013;19(13):60-6.

32. Hallander HO, Gnarpe J, Gnarpe H. Bordetella pertussis, Bordetella parapertussis, Mycoplasma pneumoniae, Chlamydia pneumoniae, and persistent cough in children. Scand J Infect Dis. 1999;31:281-6. https://doi. org/10.1080/00365549950163581

33. Braman SS. Postinfectious cough: ACCP evidence-based clinical practice guidelines. Chest 2006;129(Suppl 1):138S-46S. https://doi.org/10.1378/chest.129.1_suppl.138S

34. Newcombe PA, Sheffield JK, Juniper EF, Petsky HL, Willis C, Chang $A B$. Validation of a parent-proxy quality of life questionnaire for pediatric chronic cough (PC-QOL). Thorax. 2010;65(9):819-23. https://doi.org/10.1136/thx.2009.133868

35. Davies MJ, Fuller P, Picciotto A, McKenzie SA. Persistent nocturnal cough: A randomized controlled trial of high dose inhaled corticosteroid. Arch Dis Child. 1999;81(1):38-44. https://doi.org/10.1136/adc.81.1.38

36. Shields MD, Bush A, Everard ML, McKenzie S, Primhak R. British Thoracic Society Cough Guideline Group. BTS guidelines: Recommendations for the assessment and management of cough in children. Thorax. 2008;63(Suppl 3):1-15. https:// doi.org/10.1136/thx.2007.077370

37. Vertigan $A E$, Murad $M H$, Pringsheim $T$, Feinstein $A$, Chang $A B$, Newcombe PA, et al. Somatic cough syndrome (previously referred to as psychogenic cough) and tic cough (previously referred to as habit cough) in adults and children: CHEST guideline and expert panel report. Chest. 2015;148(1):24-31. https://doi.org/10.1378/chest.15-0423

38. Yilmaz O, Bakirtas A, Ertoy Karagol HI, Topal E, Turktas I. Children with chronic non-specific isolated cough. Chest. 2014;145(6):1279-85. https://doi.org/10.1378/chest.13-2348
39. Chang $A B$, Oppenheimer JJ, Weinberger MM, Rubin BK, Grant CC, Weir K, et al. Management of children with chronic wet cough and protracted bacterial bronchitis: CHEST guideline and expert panel report. Chest. 2017;151(4):884-90. https://doi.org/10.1016/j.chest.2017.01.025

40. Marchant J, Masters IB, Champion A, Petsky H, Chang AB. Randomised controlled trial of amoxycillin clavulanate in children with chronic wet cough. Thorax. 2012;67(8):689-93. https://doi.org/10.1136/thoraxjnl-2011-201506

41. Eg KP, Mirra V, Chang AB, Santamaria F. Editorial: Chronic suppurative lung disease and bronchiectasis in children and adolescents. Front Pediatr. 2017;5:1-3. https://doi.org/10.3389/ fped.2017.00196

42. Mansour-Ghanaie R, Fahimzad SA, Karimi A. Management of chronic cough in children. Arch Pediatr Infect Dis. 2013;1(3):136-43. https://doi.org/10.5812/pedinfect.11541

43. Ioannidis JP, Lau J. Technical report: Evidence for the diagnosis and treatment of acute uncomplicated sinusitis in children: A systematic overview. Pediatrics. 2001;108(3):E57. https:// doi.org/10.1542/peds.108.3.e57

44. Fitch PS, Brown V, Schock BC, Taylor R, Ennis M, Shields MD. Chronic cough in children: Bronchoalveolar lavage findings. Eur Respir J. 2000;16(6):1109-14. https://doi. org/10.1034/j.1399-3003.2000.16f15.x

45. Sadeghi MH, Wright CE, Hart S, Crooks M, Morice A. Phenotyping patients with chronic cough: Evaluating the ability to predict the response to anti-inflammatory therapy. Ann Allergy Asthma Immunol. 2018;120(3):285-91. https://doi. org/10.1016/j.anai.2017.12.004

46. Zhou J, Zhao X, Zhang X, Yu X, Wang Y, Jiang W, et al. Values of fractional exhaled nitric oxide for cough-variant asthma in children with chronic cough. J Thorac Dis. 2018;10(12):661623. https://doi.org/10.21037/jtd.2018.11.137

47. Rosen $R$, Vandenplas $Y$, Singendonk $M$, Cabana $M$, DiLorenzo C, Gottrand F, et al. Pediatric gastroesophageal reflux clinical practice guidelines: Joint recommendations of the North American Society for Pediatric Gastroenterology, Hepatology, and Nutrition and the European Society for Pediatric Gastroenterology, Hepatology, and Nutrition. J Pediatr Gastroenterol Nutr. 2018;66(3):516-54. https://doi. org/10.1097/MPG.0000000000001889

48. Burke JM, Jackson W, Morice AH. The role of high-resolution oesophageal manometry in occult respiratory symptoms. Respir Med. 2018;138:47-9. https://doi.org/10.1016/j. rmed.2018.03.027

49. Fracchia MS, Diercks G, Cook A, Hersh C, Hardy S, Hartnick M, et al. The diagnostic role of triple endoscopy in pediatric patients with chronic cough. Int J Pediatr Otorhinolaryngol. 2019;116:58-61. https://doi.org/10.1016/j.ijporl.2018.10.017 